THE EFFECTS OF THE CORPORATE

AVERAGE FUEL EFFICIENCY STANDARDS

Pinelopi Koujianou Goldberg

NBER Working Paper 5673

\author{
NATIONAL BUREAU OF ECONOMIC RESEARCH \\ 1050 Massachusetts Avenue \\ Cambridge, MA 02138 \\ July 1996
}

I wish to thank James Cardon and Chris Meyers for excellent research assistance, and Ashish Arora, Orazio Attanasio, Bo Honore, Gib Metcalf, Jim Poterba, and Jim Powell for helpful comments. Financial support from NSF-Grant SBR-9409339 and the Center for Economic Policy Studies at Princeton University is gratefully acknowledged. Part of the work for this project was conducted while visiting the Hoover Institution as a National Fellow. Any opinions expressed are those of the author and not those of the National Bureau of Economic Research.

(C) 1996 by Pinelopi Koujianou Goldberg. All rights reserved. Short sections of text, not to exceed two paragraphs, may be quoted without explicit permission provided that full credit, including $\odot$ notice, is given to the source. 


\title{
THE EFFECTS OF THE CORPORATE AVERAGE FUEL EFFICIENCY STANDARDS
}

\begin{abstract}
This paper examines the effects of the Corporate Average Fuel Economy Standards (CAFE) on the automobile product mix, prices, and fuel consumption. To this end, first a discrete choice model of automobile demand and a continuous model of vehicle utilization are estimated using micro data from the Consumer Expenditure Survey for 1984-1990. Next, the demand side model is combined with a model of oligopoly and product differentiation on the supply side. After the demand and supply parameters are estimated, the effects of the CAFE regulation are assessed through simulations, and compared to the effects of alternative policy instruments, such as a powerful gas guzzler tax and an increase in the gasoline tax. Our results can be summarized as follows:

Vehicle utilization is in the short run unresponsive to fuel cost changes; vehicle purchases, however, respond to both car prices and fuel cost. These results taken together imply that (1) contrary to the claims of CAFE opponents, higher fleet fuel efficiency is not neutralized by increased driving, and (2) policies aiming at reducing fuel consumption by shifting the composition of the car fleet towards more fuel efficient vehicles are more promising than policies that target utilization. Policies with such compositional effects operate through two channels: changes in vehicle prices and changes in the operating costs. Contrary to the claims of environmental groups, our results do not indicate the existence of consumer "myopia." Nonetheless, we find that the gasoline tax increase necessary to achieve fuel consumption reductions equivalent to the ones currently achieved through CAFE is $780 \%$; whether an increase of this magnitude is currently politically feasible is questionable. In general, our results indicate that the CAFE regulation was effective in reducing fuel consumption; however, shifts in the classification of products as domestic vs. imports may have weakened the effectiveness of the standards.
\end{abstract}

Pinelopi Koujianou Goldberg

Department of Economics

Princeton University

Princeton, NJ 08544-1021

and NBER 


\section{Introduction}

The Corporate Average Fuel Efficiency standard (CAFE) has caused controversy since Congress enacted it in 1975. According to the CAFE regulation, every seller of automobiles in the U.S. had to achieve by 1985 a minimum sales-weighted average fuel efficiency of 27.5 Miles per Gallon. This standard had to be achieved for domestically produced and imported cars separately. Failure to meet the prescribed standard incurred a penalty of $\$ 5$ per car per $1 / 10$ of a gallon that the corporate average fuel economy fell below the standard. ${ }^{1}$ The CAFE regulation has remained in place for the last 19 years; in fact, in recent years there has even been public debate on proposals to raise the standard up to 50 MPG. ${ }^{2}$

The original goal of the CAFE regulation was to reduce fuel consumption in a period of high oil prices. Today the rationale has shifted towards reducing consumption for environmental purposes. CAFE opponents, however, claim that regulating fuel economy may actually increase fuel consumption. ${ }^{3}$ This perverse effect could arise, for example, if the regulation increased the relative price of large cars and consumers with a strong preference for these cars switched to less fuel-efficient, used vehicles, rather than to small cars. Another possibility is that higher fuel efficiency induces consumers to drive their cars more.

In addition to affecting fuel consumption, the CAFE standard is also claimed to have trade effects. Because fuel efficient imports cannot be used to offset less efficient domestically produced cars, there is a disincentive for domestic producers to move the production of small cars abroad; in this sense, the CAFE standard has a job protection function. On the other hand, Japanese producers with fuel efficient fleets are not effectively constrained by the standard, and can therefore compete more successfully in the market for large and luxury cars that has traditionally been dominated by domestic manufacturers.

Despite the lively debate surrounding $\mathrm{CAFE}$ and the numerous articles on the subject in the public press, empirical evidence on the effectiveness of the program has been scarce and inconclusive. ${ }^{4}$ While improvements in the average fuel efficiency of the new car fleet in the 1980 s

\footnotetext{
${ }^{1}$ If, however, manufacturers exceed the minimum average required for any given model year, they are permitted to carry forward the surplus to subsequent years. In some circumstances, they are also allowed to borrow against future surpluses.

${ }^{2}$ See Crandall (1985 and 1990) for an overview of the CAFE standard regulation.

${ }^{3}$ See Crandall (1985,1990), Crandall et al (1986), Passell (1995).

${ }^{4}$ Most of the work on environmental regulation in the auto industry has focused either on theoretical arguments (e.g. Kwoka (1983)), or on the analysis of Auto Emission Standards (e.g. Gruenspecht (1982), Breshna-
} 
have been uncontroversial, the contribution of the CAFE regulation to these improvements and the implications for fuel consumption savings are still open questions. To my knowledge, only three studies have attempted to resolve these issues by estimating the short run effects of CAFE, each yielding different results: Mayo and Mathis (1988) regressed the average fleet fuel efficiency on CAFE standards and found that the CAFE coefficient was statistically insignificant; they interpreted this as evidence that the CAFE regulation was ineffective. Their results, however, refer to 1978-84, a period in which CAFE was not mandatory. Greene (1990) estimated a polynomial distributed lag model for 1978-89 to determine the relative contributions of past and current fuel price changes and CAFE standards to the fuel efficiency improvements; he found the impact of the CAFE regulation to be significant. A common feature of the two studies cited above, is that they focus on the relationship between CAFE standards and fuel economy improvements; the key question of whether these improvements led to fuel savings, remains unanswered. Yee (1991) provided a more structural treatment of the CAFE regulation, by estimating a model of the U.S. auto market using aggregate data, and employing simulations to assess the effects of alternative policy scenarios. He found that CAFE reduced fuel consumption; but the credibility of the results is limited by the fact that his approach does not model either vehicle utilization or the oligopolistic interaction between automobile manufacturers, so that the elasticities needed in the simulations have to be obtained from external sources.

An essential prerequisite for any assessment of the effects of the CAFE regulation, is knowledge of the automobile demand and supply parameters, the elasticities of substitution and vehicle utilization parameters in particular. The purpose of this paper is to obtain these parameters by estimating a model of the U.S. Automobile Industry using micro data, and use the results to analyze the short term environmental effects of CAFE standards. In particular, this project aims at addressing the following questions:

1) What are the effects of the CAFE standard on automobile prices, sales and product mix?

2) What are the expected environmental effects of the CAFE standard? In particular, what are the effects on vehicle utilization and fuel consumption? From an environmental perspective, the relevant variable is obviously not the average fuel efficiency of the new car fleet, but rather the Total Gallons consumed by U.S. drivers in a particular time interval. Expressing the fuel consumption of each driver as the product of Total Miles driven in a certain period on each car times Gallons per Mile for each car, (Miles * Gallons/Mile), allows us to address two separate han and Yao (1985), Kahn (1994)). Crandall and Graham (1989) analyzed the long term effects of CAFE by examining the impact of fuel economy rules on automobile design. 
questions: First, how do the CAFE standards affect the choice of new vehicles? (Does the CAFE regulation really lead, as claimed by its proponents, to substitution towards smaller, more fuel efficient cars?) Second, how does fuel efficiency affect vehicle utilization? If higher fuel efficiency resulted in increased driving, this would erode any beneficial effects the CAFE regulation might have.

3) How does the CAFE regulation affect the location of production?

4) How does CAFE compare to alternative fuel efficiency measures, a gasoline tax in particular?

To address the above questions I combine a disaggregate model of automobile demand and utilization with an aggregate oligopoly and product differentiation model. The theoretical framework is similar to the one developed in Goldberg (1995) with two main differences: On the demand side, I extend the model considered in Goldberg (1995) to incorporate vehicle utilization, that is miles driven on each new car purchased. On the supply side, I allow firms to employ - in addition to prices - another strategic variable: the location of production, or more accurately, the percentage of their sales that is classified as "imports" according to the EPA definition. This allows me to analyze the trade policy aspect of the CAFE regulation.

The remainder of the paper is organized as follows. Section II presents the theoretical framework and the estimation strategy in detail. Section III briefly discusses the data. In Section IV I detail the demand, utilization and supply parameters estimated using the model, and discuss their implications for questions 1-3 above. Section $V$ presents the simulation results for alternative fuel efficiency measures and assesses the effectiveness of the CAFE regulation. Section VI concludes.

\section{Theoretical Framework}

\section{II.1 Automobile Demand and Utilization}

The modelling of the consumer side of the auto market requires a unified model of vehicle choice and usage. To illustrate the necessity of such a model, consider a utilization equation of the following form:

$$
x_{i}=\alpha_{0}^{i}+\alpha_{1} p_{i}+s_{i}^{\prime} \delta+w^{\prime} \gamma_{i}+\eta
$$


The variable $x_{i}$ denotes the usage of vehicle $i$, as measured by the miles driven on that vehicle in a specific time interval. Vehicle usage will generally depend on the "price per vehicle mile", $p_{i}$, which varies by vehicle type as it is given by the product of gasoline price and Gallons per Mile, a vector $s_{i}$ of vehicle characteristics, such as horsepower, cylinders, etc., and a vector of household characteristics, $w$, such as income, family size, age, etc. A more general specification of the above equation will also include interactions of vehicle and consumer specific attributes, e.g. interactions of the "price per mile" variable with income or family size, to account for the fact that different consumers may exhibit different price elasticities depending on their value of time, income, etc. The error term $\eta$ stands for unobserved consumer characteristics, while the remaining Greek letters denote parameters to be estimated.

By estimating the above equation, one hopes to retrieve the short run price elasticity of mileage demand. In the context of a CAFE regulation analysis, the parameters of interest are the ones relating vehicle specific attributes to vehicle usage. As a result of the CAFE standards one expects the relative prices of large cars to rise, inducing a shift towards smaller, more fuel efficient cars. Consider a household, which because of this price increase switched from a large to a small car. This switch changes not only the vehicle specific attributes in the household's utilization equation (the vector $s_{i}$, and the choice dummy $\alpha_{0}^{i}$ ), but also the "price per mile" variable, since the latter depends on the fuel efficiency of the new vehicle. For an evaluation of the CAFE regulation, it is essential to know how utilization will respond to higher fuel efficiency.

Estimation of the utilization equation by OLS requires the identification assumption that the error term $\eta$ is uncorrelated with the right hand side variables. As shown by Dubin and McFadden (1984) in the context of the utilization of household appliances (demand for electricity), this assumption is unlikely to be satisfied. In particular, economic theory suggests that the error term $\eta$ should be correlated with the vehicle specific attributes in the utilization equation. Hence, estimation by OLS is inappropriate as it may result in biased coefficients.

To understand the source of this correlation, note that the demand for a durable, such as an automobile, and its usage are interdependent decisions. Demand for a vehicle arises from the flow of services provided by the vehicle's ownership. Consumers choose the car type that maximizes the utility they expect to derive from driving it; hence, the expected usage of the car is likely to affect the vehicle type choice. The intensity with which the automobile is utilized, on the other hand, depends on the vehicle type. This intensity generates derived demand 
for gasoline. Both the indirect utility the consumer derives from owning an automobile, and the intensity of the car's usage are affected by factors unobserved to the econometrician that are included in the error terms of the utility function and utilization equation respectively. If these error terms were uncorrelated, one could proceed by estimating the utilization equation by OLS, accounting for the dependence of usage on vehicle type through appropriate choice dummies, or interactions of vehicle attributes with fuel price. Yet, in practice, it is likely that the error terms of the utility and usage functions include some common unobserved attributes, that induce correlation between the two error terms, and, hence, correlation between vehicle specific attributes and the error term of the usage equation. Such unobserved factors could be safety concerns, fashion awareness, or distance to work. Concern for safety, for example, may increase the utility derived from the purchase of a large car, and hence increase the probability of its selection, while simultaneously reducing the intensity of its use.

To properly address this simultaneity issue, it is necessary to develop an integrated model of auto demand and usage; such a model does not only explicitly demonstrate the link between the two decisions, it also guides the search of appropriate instruments in the utilization equation. Consider a consumer who faces a choice between $\mathrm{N}$ mutually exclusive vehicle types. Vehicle type $i$ has an annualized cost $r_{i}$. The conditional indirect utility $U_{i}$ associated with the choice $i$ is given by a function of the following general form:

$$
U_{i}=V\left(s_{i}, w, p_{i}, y-r_{i}, \epsilon_{i}, \eta\right)
$$

where $s_{i}$ and $w$ denote, as before, vectors of vehicle and household specific attributes respectively, $p_{i}$ is the price per mile, $y$ is income, $\epsilon_{i}$ includes the unobserved attributes of alternative $i$, and $\eta$ consists of unobserved consumer characteristics. This formulation of the utility function takes into account the dependence of the vehicle choice on the price of usage, $p_{i}$.

The consumer will choose the alternative associated with the highest utility level. Hence, the probability of selecting alternative $i$ is:

$$
\operatorname{Prob}_{i}=\operatorname{Prob}\left[U_{i}\left(s_{i}, w, p_{i}, y-r_{i}, \epsilon_{i}, \eta\right)>U_{j}\left(s_{j}, w, p_{j}, y-r_{j}, \epsilon_{j}, \eta\right), \text { forj } \neq i\right]
$$

The theoretical link between demand ${ }^{5}$ and usage is provided by Roy's identity. Usage of vehicle $i$, or, equivalently, demand for miles driven on $i$, is (by Roy's identity):

\footnotetext{
${ }^{5} \mathrm{Just}$ as in the case of a continuous demand function, the discrete choice model explaing the expected value of
} 


$$
x_{i}=\frac{-\partial U_{i}\left(s_{i}, w, p_{i}, y-r_{i}, \epsilon_{i}, \eta\right) / \partial p_{i}}{\partial U_{i}\left(s_{i}, w, p_{i}, y-r_{i}, \epsilon_{i}, \eta\right) / \partial y}
$$

To empirically implement the model, it is necessary to choose a specific functional form for the utility function and specify the distribution of the error terms. The parameterization of the model was guided by three criteria. First, the functional forms should be consistent with the restrictions imposed by economic theory; in particular, the utility function should satisfy the properties of an indirect utility function. Second, the functional form assumptions should give rise to plausible substitution patterns across automobile types. Finally, the model should be computationally tractable. A specification satisfying the above criteria is the following:

$$
U_{i}=\left(\alpha_{0}^{i}+\frac{\alpha_{1}}{\beta}+\alpha_{1} p_{i}+s_{i}^{\prime} \delta+w^{\prime} \gamma_{i}+\beta\left(y-r_{i}\right)+\eta\right) e^{-\beta p_{i}}+\epsilon_{i}
$$

Application of Roy's identity to the above function yields a utilization equation that is linear in income:

$$
x_{i}=\frac{-\partial U_{i} / \partial p_{i}}{\partial U_{i} / \partial y}=\alpha_{0}^{i}+\alpha_{1} p_{i}+s_{i}^{\prime} \delta+w^{\prime} \gamma_{i}+\beta\left(y-r_{i}\right)+\eta
$$

The error term $\epsilon_{i}$ is assumed to follow the generalized extreme value distribution. This distributional assumption gives rise to a nested logit structure for the automobile choice model. In the following, I discuss the properties and advantages of this specification in more detail.

\section{The Automobile Choice Model:}

The utility specification in (1) allows us to derive a discrete choice model of automobile demand; to this end, it is useful to rewrite the indirect utility function $U_{i}$, as the sum of two components, a deterministic component $V_{i}$, and a stochastic term $u_{i}$.

$$
U_{i}=V_{i}+u_{i}
$$

where $V_{i}=\left(\alpha_{0}^{i}+\frac{\alpha_{1}}{\beta}+\alpha_{1} p_{i}+s_{i}^{\prime} \delta+w^{\prime} \gamma_{i}+\beta\left(y-r_{i}\right)\right) e^{-\beta p_{i}}$. The presence of the vehicle specific term $e^{-\beta_{p_{i}}}$ in equation (1) complicates the specification; because this term is multiplied by the

the quantity purchased. In the discrete choice context, demand for a specific vehicle is, at the individual level, represented by an indicator variable that takes the value 1 if this alternative is purchased, and 0 otherwise. The expected value of this variable is the probability of selecting the corresponding alternative. The terms demand and selection probability are therefore used interchangeably here. 
error term of the utilization equation $\eta$, the composite error term of equation (1) becomes

$$
u_{i}=\eta e^{-\beta_{i}}+\epsilon_{i}
$$

Unfortunately, the distribution of the new error term $u_{i}$ does not preserve the computational advantages of the generalized extreme value distribution I assumed for the term $\epsilon_{i}$. To retain these advantages, I follow the approach suggested by Mannering and Winston (1985) and apply a Taylor series expansion around the mean price per mile $(\bar{p})$. Assuming that the higher-order terms are not significant, ${ }^{6}$ the composite error term becomes $u_{i}=\eta e^{-\beta \bar{p}}+\epsilon_{i}$. The advantage of this formulation is that the first component of the composite error term, $\eta e^{-\beta \bar{p}}$, does not vary by vehicle, and therefore does not affect the selection probabilities.

Given the assumption of a generalized extreme value distribution for the error terms $\epsilon$, the selection probabilities are given by the nested logit formulas. ${ }^{7}$ In particular, the vehicle choice model is nested according to Figure 1 . The reason for adopting this nesting structure is that a similar model was estimated in Goldberg (1995) and tested against alternative specifications. The model was shown to fit the data quite well and give rise to plausible own and cross price elasticities.

Figure 1: Automobile Choice Model

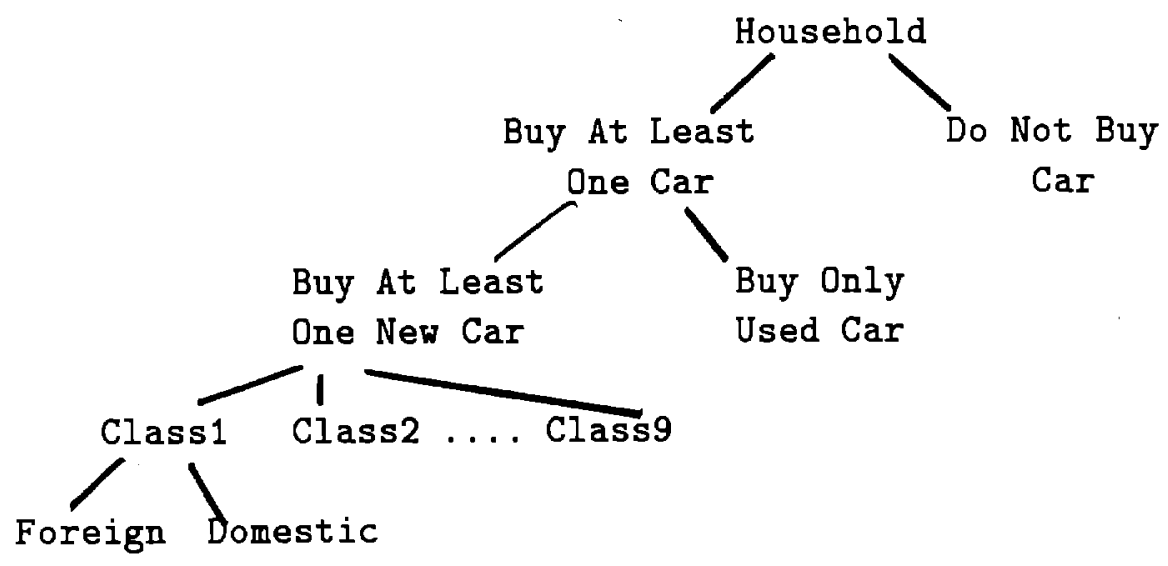

The set of vehicles is partitioned into $k$ disjoint subsets according to the criteria of newness $(n)$, market segment (c), and origin (o), so that each vehicle type is indexed by a triple

\footnotetext{
${ }^{6}$ This will generally be the case if the variation in the prices $p_{i}$ is not too large.

${ }^{7}$ The proof of the above statement is provided in McFadden (1981).
} 
subscript, $(n, c, o)$. In accordance with automobile industry publications, the empirical analysis distinguishes between nine market segments (Clas1-Clas9): subcompacts, compacts, intermediate, standard, luxury, sports, pick-up trucks, vans, and miscellaneous (models like utility vehicles that are not assigned to any of the previous categories). This classification is based primarily on vehicle characteristics and prices. ${ }^{8}$

The joint probability of choosing a new vehicle type $(n, c, o)$ is:

$$
P_{n, c, o}=P_{b} * P_{n / b} * P_{c / n, b} * P_{o / c, n, b}
$$

where $P_{n, c, o}$ denotes the joint probability of a household selecting the vehicle type $(n, c, o), P_{b}$ is the marginal probability of purchasing an automobile during the current year, $P_{n / b}$ is the probability of buying a new car conditional on buying a car, and $P_{c / n, b}$, and $P_{o / c, n, b}$, represent probabilities of selecting class and origin respectively, conditional on the previous stage decision.

As shown in McFadden (1981), the assumption of the generalized extreme value distribution implies that the conditional choice probabilities at each node of the tree, as well as the marginal probability of purchasing a car, will be given by multinomial logit formulas. The link between subsequent nodes of the tree is provided by the inclusive value terms, which measure the expected aggregate utility of each subset; the coefficients of the inclusive value terms, which are estimated along with the other parameters of the model, reflect the dissimilarity of alternatives belonging to a particular subset. As McFadden has shown (1981), the nested structure depicted in Figure 1 is consistent with random utility maximization if and only if the coefficients of the inclusive value terms lie within the unit interval. As the dissimilarity coefficients approach 1 , the distribution of the error terms tends towards an iid extreme value distribution and the choice probabilities are given by the simple multinomial logit model. As the coefficients approach 0 , the error terms become perfectly correlated and consumers choose the alternative with the highest strict utility. If the parameters of the inclusive values are greater than 1 , there is substitution across the nests and, as noted above, the nesting is not consistent with utility maximization. ${ }^{9}$

\footnotetext{
${ }^{8}$ It should be noted here that this classification is somewhat subjective; it does not correspond exactly to the segmentation proposed in the Automotive News Market Data Book (ANMDB) under "EPA Mileage Ratings for 198* Models" in which the only criterion for defining market segments is fuel efficiency (defined as Miles per Gallon (MPG) ). The latter classification suffers from the obvious shortcoming that it groups together products with very different characteristics, such as a BMW and a Toyota Corolla. In addition to MPG, I use information on prices, body type and size, as reported elsewhere in the ANMDB, to assign vehicles to one of the above categories.

${ }^{9}$ The nesting of Figure 1 does not imply that consumers actually make decisions sequentially; the nesting
} 
The computational burden associated with the estimation of the above model can be significantly reduced by employing sequential maximum likelihood to decompose estimation in four stages. It is well known that this procedure results in consistent (though not efficient) parameter estimates but fails to produce consistent estimates of the covariance matrix; to correct the latter, the recursive formulas derived in McFadden (1981) were applied.

The demand model differs from other logit analyses common to this literature, in that it adopts a transactions rather than a holdings approach. This offers two advantages: The modelling of the first stage of the decision process (purchase of a vehicle) incorporates an outside good in the demand estimation; the outside good represents the possibility that consumers forego the purchase of a car by holding onto their older vehicles. Taking this possibility into account is crucial in deriving the effects of environmental regulation, given that I do not explicitly model scrappage decisions. Scrappage receives in the current framework a reduced form treatment: Suppose a consumer decides to scrap a vehicle in the current stock to purchase another car; this will appear in our framework as a positive observation in the first node of the tree, and, depending on whether the consumer buys a new or used car, it will also enter the subsequent nodes of the tree. If, on the other hand, the consumer decides to postpone scrappage, this will appear as a "no purchase" decision in the first node; hence, to the extent that the probability of scrappage is linked to the probability of buying another car, modelling of the outside good takes that into account. The second advantage of the transactions approach is that it allows for a better treatment of dynamics as it utilizes data on past purchases; information on previous automobile holdings for each household is incorporated in the model, accounting for the temporal dependence in the automobile choice process. Such information includes the number of cars the household currently owns, the average age of the stock, the age of the newest car, etc.

The primary focus of the model is on demand for new vehicles. Used vehicles do enter the model, both as parts of the current automobile holdings and as substitutes for new cars at the second node of the tree. Hence, it is possible to derive the elasticities of substitution between new and used cars. The modelling of used car purchases in the second stage of the tree, in conjunction with the presence of the "outside" good in the first node, allows us to address the "Gruenspecht" effect of the CAFE regulation, that is the regulation's impact on the vehicle

reflects correlation patterns among unobserved factors across alternatives as they result from patterns in the econometrician's lack of information rather than from the household's decision process. 
stock composition through its effects on scrappage and new car purchase decisions. ${ }^{10}$

The nested structure of the automobile choice model places less structure on the car selection process than simple multinomial logit models. It does so by dropping the assumption of "independence of irrelevant alternatives (IIA)". The nested logit structure assumes instead, that choices within each stage are similar in unobserved factors, so that IIA holds for any pair of alternatives within each stage, but not for the entire choice set. ${ }^{11}$ The relaxation of the IIA property translates into more plausible substitution patterns, enabling the econometrician to capture the consumer specific response to unobserved characteristics that are common to products within a specific class.

Two of the parameter estimates of the discrete choice model are of special interest: the coefficient on "Price per Vehicle Mile", and the coefficient on vehicle price. ${ }^{12}$ The first one gives insight into consumer preferences for fuel efficiency; the second one allows us to derive the elasticities of substitution between various vehicle types, and thus assess the effects that price changes resulting from the imposition of the CAFE standard may have on the composition of the new car fleet. Our approach assumes that vehicle prices are econometrically exogenous in the estimation of micro level demand functions. ${ }^{13}$ This assumption is justified if the error term of the utility function does not include a common across households, aggregate component; such a component could, for example, arise from unobserved product quality or macroeconomic shocks. The use of micro data allows us to control for this aggregate component in the error term, by including macro variables (GNP, employment rates, etc..) and vehicle fixed effects in the specification. ${ }^{14}$

A noteworthy difference between the model estimated here and the one of Goldberg (1995), is that the nested logit of Figure 1 does not incorporate the choice between vehicle models at the very last stage, but rather stops with the choice between Domestic and Foreign; the latter choice is assumed to depend on averages of vehicle characteristics. ${ }^{15}$ This aggregation was

\footnotetext{
${ }^{10}$ See Gruenspecht (1982).

${ }^{11}$ See McFadden (1981).

${ }^{12}$ Vehicle prices enter the model through the annualized cost variable; along with vehicle specific dummies (country of origin dummies, for example) vehicle prices are used as proxies for the annualized cost of the new vehicles.

${ }^{13}$ The exogeneity of prices in the econometric sense at the estimation level is not to be confused with the endogeneity of prices in the automobile market model; at the simulation stage, prices are treated as endogenous variables and their equilibrium values are solved for.

${ }^{14}$ See Goldberg (1995) for a detailed discussion of this issue.

${ }^{15}$ The nesting of Figure 1 results, in fact, in quite homogeneous vehicle classes; the vehicle models included in each subset at the last stage have approximately the same fuel efficiency, the same cylinders and horsepower,
} 
considered necessary to reduce the computational burden associated with solving for the equilibrium in the automobile market (see Section V). This simplification limits the applicability of the results as it precludes an evaluation of the CAFE effects for different corporations. Anecdotal evidence suggests that there was some variation in the impact of the CAFE regulation across corporations, with Chrysler being the least restrained as it produces a higher share of small cars. ${ }^{16}$ Yet, the political debate surrounding CAFE is often cast in terms of the nationality of the auto manufacturers; domestic manufacturers, for example, claim that the current regulation reduces their competitiveness at the benefit of the Japanese. Such questions, as well as the environmental aspect of the CAFE regulation, can still be addressed within the current framework.

\section{The Utilization Equation:}

To account for the potential endogeneity of the choice specific explanatory variables in the utilization equation, equation (2) is estimated by instrumental variables and a reduced form method along the lines proposed in Dubin and McFadden (1985). ${ }^{17}$ To this end, it is helpful to rewrite equation (2) as

$$
x_{i}=\sum_{j}\left(\alpha_{0}^{j}+\alpha_{1} p_{j}+s_{j}^{\prime} \delta+w^{\prime} \gamma_{j}+\beta\left(y-r_{j}\right)\right) \psi_{j}+\eta
$$

where $j$ stands for the various alternatives available to the household, and $\psi_{j}$ is a dummy equal to 1 if $i=j$. When the instrumental variable method is used, the estimated probabilities $\hat{P}_{j}$ from the discrete choice model are used as instruments for $\psi_{j}$. The validity of the estimated probabilities as instruments in the estimation of the usage equation stems from the fact, that these probabilities represent the expected values of a household's demand for particular vehicle types; ${ }^{18}$ as such they are by definition orthogonal to the error terms of the demand equations.

the same prices. The main differences across vehicle makes belonging to the same class are related to the option packages offered and, of course, to their brand. See also Goldberg (1995).

${ }^{16}$ This is due to the fact that Chrysler took preemptive steps in the 1980s to avoid being CAFE constrained by shifting its production mix towards small cars. In contrast, GM and Ford concentrated their efforts in lobbying against the CAFE regulation.

${ }^{17}$ The utilization equation focuses on new cars alone; information on the mileage of used cars is available in the CES, the information on used car characteristics, is, however, not detailed enough to allow estimation of the utilization equation inclusive of used cars. For example, the CES does not report the exact production year for used cars, so that the fuel efficiency of the used car models is unknown.

${ }^{18}$ As mentioned above, in the discrete choice framework, demand for a particular vehicle type at the individual level corresponds to an indicator variable, which is 1 when this vehicle type is purchased and 0 otherwise. The expected value of this indicator variable is the probability of choosing that alternative. 
In the reduced form approach, OLS is applied to the equation ${ }^{19}$

$$
x_{i}=\sum_{j}\left(\alpha_{0}^{j}+\alpha_{1} p_{j}+s_{j}^{\prime} \delta+w^{\prime} \gamma_{j}+\beta\left(y-r_{j}\right)\right) \hat{P}_{j}+\xi
$$

Both methods yield consistent parameter estimates if the choice dummies $\psi_{j}$ and the error term $\eta$ are correlated.

In summary, estimation of the consumer level model involves two steps: First, the vehicle choice model is estimated. The estimation results from this stage are used in calculating the predicted probabilities of choosing particular vehicle types. Second, the utilization equation is estimated, by a reduced form method or by instrumental variables, using the predicted probabilities of vehicle choice as instruments.

\section{II.2 Supply and Market Equilibrium}

The link between demand and supply is provided by aggregate demand; the latter is the sum of the demands of individual consumers, and is computed as the weighted sum of vehicle selection probabilities: ${ }^{20}$

$$
D_{n, c, o}=\sum_{h} P_{n, c, o}^{h} w^{h}+\sum_{h} \nu_{n, c, o}^{h} w^{h}
$$

where $D_{n, c, o}$ represents the aggregate demand for vehicle type $(n, c, o), w^{h}$ is the individual household weight that is provided by the micro survey and reflects the representativeness of consumer $h$ in the U.S. population, $P_{n, c, o}^{h}$ is the probability that consumer $h$ selects vehicle type $(n, c, o)$, and $\nu_{n, c, o}^{h}$ is a stochastic i.i.d component that measures deviations of the actual from the expected demand.

Similarly, expected aggregate demand is given by:

\footnotetext{
${ }^{19}$ In the actual empirical work, the variable $p_{j}$ will be interacted with demographic characteristics. See Section IV.

${ }^{20}$ As mentioned earlier, individual demand in the discrete choice framework corresponds to an indicator variable, which assumes the value 1 when a particular vehicle type is purchased. This indicator variable can, in turn, be expressed as the sum of its expected value (the probability of vehicle selection) and a stochastic component that represents the deviation of the expected from the actual value.
} 


$$
E D_{n, c, o}=\sum_{h} P_{n, c, o}^{h} w^{h}
$$

On the supply side, the automobile industry is modelled as an oligopoly with multiproduct firms. It is assumed that each period firms maximize profits myopically with respect to two variables: prices and the fraction of their production classified as domestic according to the EPA definition (domestic content). In particular, given expected aggregated demand $E D_{i}$, firms choose the fraction $\alpha_{i}$ that will be characterized as domestic, and the fraction $\left(1-\alpha_{i}\right)$ that will be classified as imported. Our treatment of $\alpha_{i}$ as a choice variable abstracts from capacity installment or utilization issues, as it presumes that shifts in the origin of a firm's inputs can be decided and executed within a short period; this is a reasonable assumption, if firms already operate production plants both domestically and abroad. ${ }^{21}$ The distinction between domestic and imported products corresponds to the way "imports" are defined by the EPA. The classification criterion used in the implementation of the CAFE standards is not location of production, but domestic content; cars with 75 percent or more Canadian and U.S. content are treated as domestic. It is interesting to note that this criterion differs from the one used in the application of the VERs, or the one used by the U.S. Treasury Department for duty purposes (country of assembly). ${ }^{22}$ This multiplicity of "import" definitions supports the modelling of domestic content decisions as being dependent on the CAFE regulation, given that the implementation of other policies (VERs, for example) is based on different classification criteria.

The assumption that firms use prices and import classification as strategic variables reflects the focus of the paper on the short term effects of the CAFE standards. In the short run, vehicle characteristics are assumed to be fixed; in the longer run, firms have, of course, the opportunity to vary vehicle characteristics in response to environmental regulation, by developing new technologies that may combine fuel efficiency with larger size or horsepower. Our approach abstracts from the development of such technologies as well as the choice of characteristics other

\footnotetext{
${ }^{21}$ A priori, it seems unlikely that auto manufacturers would establish plants in foreign countries only to avoid CAFE penalties; the anecdotal evidence suggests that other considerations, such as exchange rate movements, or restrictive trade policies had a larger impact on foreign direct investment (FDI). Our approach does not attempt to model FDI; instead, the existence of foreign plants is taken as given when manufacturers consider shifts in the domestic content of their vehicles. In this sense, it is not unreasonable to presume that environmental regulation has a considerable impact on domestic content decisions.

${ }^{22}$ The implications of these definitions can be best illustrated in the case of the Nissan Sentra. This model is assembled in the U.S, and therefore excluded from the VER related calculations; nevertheless, the product is - with exactly $74 \%$ domestic content - treated as an import by the EPA. Similarly, the Honda Accord and Toyota Camry are produced both abroad and in the U.S., but the combined fleet is in both cases treated as imported by the EPA.
} 
than prices, as this would complicate the analysis considerably; ${ }^{23}$ the focus is instead on the short run responses of the firms, that is the shift in the product mix and import classification.

Given the aggregation of vehicle types according to market segments and origin, it is reasonable to distinguish between two types of firms, Domestic and Foreign, with each firm offering a product mix corresponding to the market segments discussed above. The equilibrium concept is Nash. In the presence of the CAFE standard the profit maximization problem takes the following form: ${ }^{24}$

$$
\max _{\vec{\alpha}_{i}, \vec{p}_{i}}\left\{\sum_{i=1}^{n_{f}}\left[p_{i} q_{i}-\alpha_{i} q_{i} c_{i}-\left(1-\alpha_{i}\right) q_{i} c_{i}^{*}\right]-F_{f}\right\}
$$

where $q_{i}$ denotes production, $n_{f}$ is the number of products produced by firm $f, F_{f}$ denotes the firm's fixed $\operatorname{costs}^{25}$ (for both domestic and foreign operations), $c_{i}$ is the unit variable cost for the fraction of product $i$ classified as domestic, and $c_{i}^{*}$ is the unit variable cost for the fraction of $i$ classified as imported, expressed in U.S. currency. Assuming firms set production equal to expected demand, $q_{i}$ can be replaced by $E D_{i} \cdot{ }^{26}$

One way to introduce CAFE standards in the supply side is to formulate a constrained maximization problem for auto manufacturers (firms maximize profits subject to the constraint that their average fuel efficiency is greater than or equal to the prescribed standard), and estimate the associate Kuhn-Tucker multipliers. Such a formulation would, however, be inconsistent with the current regulation, as the latter allows producers to fall short of the standard at the cost of high penalties. Furthermore, the actual figures on the achieved fuel efficiency of automobile manufacturers are not consistent with a model predicting a mass at the point where

\footnotetext{
${ }^{23}$ See Bresnahan and Yao (1985) for an analysis of the effects of fuel economy standards on vehicle characteristics.

${ }^{24}$ The relevant prices in the supply side of the model are the wholesale prices; the demand side estimation, on the other hand, uses transactions prices. Wholesale prices are obtained by applying dealer margins on the suggested retail prices. See Goldberg (1995) for more details on this issue.

${ }^{25}$ The latter drop out from the first order conditions of the profit maximizing firms; therefore it is not necessary to further specify their functional form.

${ }^{26}$ The above profit maximization expression refers to a domestic firm. Similar conditions apply to foreign firms. All monetary variables are expressed in U.S. dollars, so that exchange rates do not enter the specification. This formulation of the profit maximization condition ignores the presence of the VER on Japanese autos. As I discuss in the data section, however, the empirical analysis concentrates on the 1985-1990 period. Anecdotal and empirical evidence suggest that the VER had much weaker - if any - effects after 1985; consistent with this evidence is also the fact that the Japanese, without any particular pressure from the American government, volunteered to extend the VER for a few more years in 1985. To the extent that the VER was not binding after 1985, ignoring it in the profit maximization formulation does not entail any loss of information.
} 
the constraint becomes binding; while Japanese corporations consistently exceed the prescribed fuel efficiency, corporations such as GM and Ford are often well below the standard. ${ }^{27}$ These considerations argue for modelling the CAFE constraint as part of the cost function.

In particular, the variable unit cost function for product $i$ is modelled as follows:

$$
\begin{gathered}
c_{i}=n c_{i}+50 I_{1}\left(C A F E-\frac{\sum_{j=1}^{n_{f}} \alpha_{j} \dot{q}_{j} F E_{j}}{\sum_{j=1}^{n_{f}} \alpha_{j} q_{j}}\right)+u_{i} \\
c_{i}^{*}=n c_{i}^{*}+50 I_{2}\left(C A F E-\frac{\sum_{j=1}^{n_{f}}\left(1-\alpha_{j}\right) q_{j} F E_{j}}{\sum_{j=1}^{n_{f}}\left(1-\alpha_{j}\right) q_{j}}\right)+u_{i}^{*}
\end{gathered}
$$

The terms $n c_{i}$ and $n c_{i}^{*}$ denote the unit variable costs for the "domestic" and "imported" fraction of product $i$ in the absence of CAFE constraints; these components are assumed to be constant. ${ }^{28} 29$ The terms $u_{i}$ and $u_{i}^{*}$ are stochastic i.i.d. components, observed by the firm, but unobserved by the econometrician.

The CAFE regulation introduces a discontinuity in the cost function, at the point where the constraint becomes binding. This is captured by the last two terms in the above equations; CAFE denotes the standard and FE is the fuel efficiency of individual vehicle types as measured by MPG. $I_{1}$ and $I_{2}$ are dummy variables which are equal to one if $\frac{\sum_{j} \alpha_{j} q_{j} F E_{j}}{\sum_{j} \alpha_{j} q_{j}}<C A F E$ and $\frac{\sum_{j}\left(1-\alpha_{j}\right) q_{j} F E_{j}}{\sum_{j}\left(1-\alpha_{j}\right) q_{j}}<C A F E$ respectively. The terms $50 I_{1}\left(C A F E-\frac{\sum_{j} \alpha_{j} q_{j} F E_{j}}{\sum_{j} \alpha_{j} q_{j}}\right)$ and $50 I_{2}(C A F E-$ $\left.\frac{\sum_{j}\left(1-\alpha_{j}\right) q_{j} F E_{j}}{\sum_{j}\left(1-\alpha_{j}\right) q_{j}}\right)$ reflect the penalties associated with not meeting the standard. As mentioned in the Introduction, this penalty is $\$ 5$ per car for each $1 / 10$ of a gallon that the corporate average fuel economy falls below the standard.

The non-differentiability of the cost function at the point where the CAFE standard becomes binding, complicates the characterization of the equilibrium conditions. In general, we can distinguish between two cases. In the first case, there is an interior solution, which may or may not involve CAFE penalties; in the second case, the solution occurs on the boundary separating

\footnotetext{
${ }^{27}$ Or, more accurately, they would have been well below the standard, if this had not been decreased as a result of their lobbying efforts.

${ }^{28} \mathrm{Hence}$, in the absence of binding CAFE standards, the unit variable costs are equal to the marginal costs.

${ }^{29}$ These components include everything that affects unit costs, expect for environmental standards; for example, $n c_{i}^{*}$ may include unit transportation costs if the so called "import" is produced abroad. The components $n c_{i}$ and $n c_{i}^{*}$ will generally be functions of vehicle characteristics and input prices.
} 
the region in which the CAFE-standard is met from the one where the constraint is not satisfied. Within each of the above cases, we can can make further distinctions depending on whether the constraint is satisfied (or binding) for domestic products only, imports only, or both.

The reason we need to characterize the equilibrium at this stage of the project is to obtain the unit variable costs of production (both gross and net of CAFE penalties). This task can be substantially simplified by making the following observation: For each year in our sample, the fractions of domestic and foreign production, $\alpha_{i}$ and $\left(1-\alpha_{i}\right)$, are data. Once the demand side of the model is estimated, the expected aggregate sales for each product, $E D_{i}$ are also data. Given this information, the firm's estimate of its average fuel economy can easily be computed; the latter is $\frac{\sum_{j} \alpha_{j} E D_{j} F E_{j}}{\sum_{j} \alpha_{j} E D_{j}}$ for the firm's domestic products, and $\frac{\sum_{j}\left(1-\alpha_{j}\right) E D_{j} F E_{j}}{\sum_{j}\left(1-\alpha_{j}\right) E D_{j}}$ for its imports. If these fuel economy figures lie below or above the CAFE standard, then we know that we have an interior solution. In other words, to the extent that the prescribed standard is not met exactly by the firm, the equilibrium occurs in the differentiable area of the profit function. ${ }^{30}$. This indeed turns out to be the case in the data; both our estimates and actual data on the achieved fuel economies of automobile manufacturers imply interior solutions for every single year in our sample. Hence, for the purpose of obtaining the unit variable costs, we can restrict ourselves to characterizing equilibria in the differentiable area of the profit function. ${ }^{31}$ In this case, differentiation of the profit function with respect to $p_{i}$ and $\alpha_{i}$ yields the following first order conditions:

$$
\begin{aligned}
\frac{\partial \pi^{f}}{\partial p_{i}} & =E D_{i}+\sum_{j=1}^{n_{f}}\left(p_{j}-\alpha_{j} c_{j}-\left(1-\alpha_{j}\right) c_{j}^{*}\right) \frac{\partial E D_{j}}{\partial p_{i}}-\sum_{j=1}^{n_{f}} \alpha_{j} E D_{j} \frac{\partial c_{j}}{\partial p_{i}}-\sum_{j=1}^{n_{f}}\left(1-\alpha_{j}\right) E D_{j} \frac{\partial c_{j}^{*}}{\partial p_{i}}=0(5) \\
\frac{\partial \pi^{f}}{\partial \alpha_{i}} & =-c_{i} E D_{i}+c_{i}^{*} E D_{i}-\sum_{j=1}^{n_{f}} \alpha_{j} E D_{j} \frac{\partial c_{j}}{\partial \alpha_{i}}-\sum_{j=1}^{n_{f}}\left(1-\alpha_{j}\right) E D_{j} \frac{\partial c_{j}^{*}}{\partial \alpha_{i}}=0 \quad i=1, \ldots, n_{f}
\end{aligned}
$$

Equation (5) is the standard first order condition in a Bertrand game. Note that in the presence of the CAFE standard, marginal costs (though constant when the CAFE penalty is not incorporated) depend on the allocation of production across vehicle types with different fuel efficiencies, and therefore on relative prices; this effect is captured through the last two terms

\footnotetext{
${ }^{30}$ For example, if the CAFE standard is 26.0 MPG, and a firm has an average fuel economy of 25.0 MPG for its domestic products and 27.0 MPG for its imports, then we know that we have an interior solution with $I_{1}=1$ and $I_{2}=0$.

${ }^{31} \mathrm{~A}$ complete characterization of the equilibrium configurations is available upon request; given that we never observe boundary solutions in the data, the derivation of the equilibrium conditions for this case was omitted from the paper for expositional reasons.
} 
in equation (5). Equation (6) also has an intuitive interpretation; the first and the third terms represent the additional cost associated with infinitesimally increasing the fraction of production classified as domestic, at the expense of production classified as imported; this additional cost is at the equilibrium counterbalanced by the cost savings resulting from reducing production of imports (second and fourth terms). Note also that if a firm's average fuel economy exceeded the CAFE standard, the last two terms in (6) would be zero. Equation (6) would then reduce to the standard arbitrage condition of international production, stating that at the equilibrium marginal costs of production for domestic and imported products have to be equal, if a firm is observed to produce the same product in more than one locations; ${ }^{32}$ otherwise there would be an incentive for manufacturers to shift production to the "lower cost" country. In the presence of the CAFE standard this arbitrage condition becomes slightly more complicated, as it is potentially beneficial for a firm to shift production towards a "more expensive" country, so as to reduce the CAFE penalty. This effect is captured through the last two terms in (6).

Given that the data indicate the presence of interior solutions, it is easy to retrieve the unit variable costs using the first order conditions of the profit maximizing producers, equations (5) and (6): If we have $N$ products, the first order conditions define a system with $2 N$ equations and $2 N$ unknowns, namely the unit costs of production for domestic and imported products. Since these first order conditions have to hold at the equilibrium exactly, they can be solved for the unit costs.

To summarize, the empirical strategy involves the following steps. First, the discrete choice model of Figure 1 and the continuous utilization model are estimated; as noted earlier, the estimation results from this step are interesting in their own right. Next, the parameter estimates are used in conjunction with the population weights provided in the CES to compute the expected aggregate demand according to Formula (4). This expression is then substituted into the first order conditions of the profit maximizing producers, to solve for the unit variable costs. In the same step, we compute the average fuel efficiency of each firm as implied by the model, compare it to published figures, and use it to infer the CAFE penalty term entering the unit cost formula. Having retrieved the unit costs both gross and net of CAFE penalties, the effects of alternative policy scenarios are then addressed through counterfactual simulations.

\section{Data}

\footnotetext{
${ }^{32}$ Recall that in this case $c_{i}=n c_{i}$ and $c_{i}^{*}=n c_{i}^{*}$.
} 
The primary data source for this project is the Consumer Expenditure Survey (1984-1990) conducted by the Bureau of Labor Statistics. The survey includes detailed information on the demographics and automobile holdings of about 7,000 distinct households per year. The information on automobiles includes the make/model and purchase price of each car, financing, disposal of old vehicles, and a large set of vehicle characteristics. Most importantly, the CES includes the mileage of each car owned by the household during each quarter. ${ }^{33}$ This information is used to derive a measure of the utilization of each new car purchased; to measure the utilization of the new car, I average its mileage across the quarters following its purchase. This procedure makes the results less sensitive to reporting error or extraordinary utilization in a single quarter. The mean utilization of new cars in the CES sample is 2252 miles per quarter, while the median is 1900 miles. Details about the data set as well as tables with summary statistics can be found in Goldberg (1995).

The CES file is supplemented by a data set on vehicle characteristics based on the Automotive News Market Data Book. The latter includes information on size, performance, fuel efficiency and standard options of various models and is used to construct the averages that are used in the demand estimation. Information on gasoline prices by region (incl. state and local taxes) is taken from the Statistical Abstract. This information is needed to compute the "Price per Mile" for each vehicle. A big advantage of focusing on the 1985-1990 period is that it includes the sharp decline of gas prices at the end of 1985 so that there is ample variation in the data to identify the consumer responses to lower operating vehicle cost.

Institutional details about the implementation of the CAFE standard as well as information about the classification of vehicles according to the "domestic content" criterion are taken from the Automotive News Market Data Book and Ward's Automotive Yearbook. This information is summarized in Table 1. The first column reports the effective CAFE standards for passenger cars for 1985-1990; the corresponding standard for trucks was 20 MPG during that period. The standards implemented in each year often deviate from what was initially announced by the Department of Transportation (DOT). In 1986, for example, GM and Ford petitioned DOT to lower CAFE; the DOT responded by lowering the standard from the initially announced 27.5 MPG down to 26 MPG for the 1986-1988 period, and to 26.5 MPG for 1989.

Columns 3-10 in Table 1 report the percentage of American cars that are produced domestically as opposed to a foreign country. An interesting feature of the EPA classification rules

\footnotetext{
${ }^{33}$ Each household is interviewed in the CES for four consecutive quarters.
} 
is that as of 1990 there were no foreign brands classified as "domestic", and this despite the expansion of foreign transplants in the U.S. after 1987; even when certain models qualified as domestic according to the "domestic content" criterion (this is, for example, the case with the Honda Accord or the Toyota Camry), the EPA treated the combined fleet as imported. This implies that the variable $\alpha_{i}$ in the profit maximization conditions, indicating the fraction of production located in the U.S., is always zero in the case of foreign manufacturers. As for American cars, there has been a steady trend in the 1980's towards increasing the share of small cars produced abroad, but at the same time, the share of large cars produced abroad has increased too. This latter phenomenon has often been attributed to the existence of the CAFE standard.

Table 1: CAFE Standards and Shares of Domestically Produced Cars, 1985-90

\begin{tabular}{|c||c||c|c|c|c|c|c|c|c|c|}
\hline \multicolumn{1}{|c||}{} & \multicolumn{1}{c||}{ CAFE Standards } & \multicolumn{5}{c|}{ Fraction of American Cars Produced in the U.S. } \\
\hline \hline & & Subc & Comp & Intm & Std & Lux & Spor & Trck & Van & Oth \\
\hline & & 0.877 & 1.000 & 1.000 & 0.896 & 1.000 & 1.000 & 0.981 & 1.000 & 1.000 \\
85 & 27.5 & 0.818 & 1.000 & 0.998 & 0.911 & 1.000 & 1.000 & 0.979 & 1.000 & 1.000 \\
86 & 26.0 & 0.777 & 0.983 & 0.995 & 0.907 & 0.995 & 1.000 & 0.980 & 1.000 & 1.000 \\
87 & 26.0 & 0.641 & 0.961 & 0.987 & 0.819 & 0.997 & 1.000 & 0.986 & 1.000 & 0.993 \\
88 & 26.0 & 0.596 & 0.953 & 0.905 & 0.832 & 0.995 & 0.990 & 0.991 & 1.000 & 0.965 \\
89 & 26.5 & 0.753 & 0.939 & 0.999 & 0.871 & 0.961 & 0.981 & 0.996 & 1.000 & 0.996 \\
90 & 27.5 & &
\end{tabular}

\section{Empirical Results}

\section{TV.1 Results from the Estimation of the Discrete Choice Model}

The discrete choice model of Figure 1 was estimated by sequential maximum likelihood in four steps each of which corresponds to a branch of the tree depicted in Figure 1. The parameter estimates, standard errors ${ }^{34}$ and t-statistics are reported in Appendix B, Tables B1B4; a complete list of the variables included in the estimation is provided in Appendix A.

At the first stage of the estimation (domestic vs. foreign) the specification includes vehicle attributes, (price, horsepower divided by weight, car size, price per vehicle mile), household characteristics (age, education, family size, regional dummies, employment status, income and

\footnotetext{
${ }^{34}$ The standard errors were corrected using the recursive formulas derived in McFadden (1981).
} 
assets, population size), year dummies, and market segment specific dummies. Interactions of household and vehicle characteristics (e.g. horsepower * age, family size * vehicle size, etc.) was also experimented with, but these interactions were statistically insignificant and therefore dropped from the specification. The statistical insignificance of these interactions is not surprising given that household characteristics are included directly in the estimation. The coefficients associated with these characteristics are choice specific, and as such they already represent interactions of household and vehicle specific attributes; the age coefficient, for example, informs us how the probability of buying a foreign car changes with age. In addition, the specification includes a dummy variable which assumes the value 1 if the household has purchased a similar vehicle type in the past; this variable is highly significant indicating that past purchases have a significant impact on current choices. ${ }^{35}$

At higher stages, the explanatory variables consist of household characteristics, year dummies, macroeconomic variables (personal disposable income, unemployment rate, interest rate for auto loans), and the inclusive value terms. Ownership dynamics which become increasingly important as we move towards the top of the tree, are accounted for by variables related to the existing vehicle stock. These include the number of cars currently owned, the age of the newest car, the average age of the stock, and the square terms of the above variables which account for nonlinear depreciation schemes. In the absence of any information on maintenance or repair costs, such variables act as proxies for the condition of the existing vehicle stock; this presumably plays a big part in the decision to purchase a new car vs. hold onto the old vehicles.

In general, the parameters are precisely estimated and the results seem consistent with conventional wisdom. For example, the results from the estimation of the domestic vs. foreign branch confirm the belief that foreign cars are most popular in the West and among high income households. Similarly, the results from the estimation of the market segment branch indicate that large households are more likely to purchase large cars, while luxury automobiles are preferred by high income consumers. The choice between a new and used car seems to be primarily dictated by financial ability; this is also true, but to a lesser extent, for the buy vs. not buy decision. The coefficients on the inclusive value terms are (with one exception) between 0 and 1 , thus supporting the nesting sequence adopted in the modelling of the demand side; the exception refers to the first node of the tree (buy vs. not buy), where the estimated coefficient

\footnotetext{
${ }^{35}$ This finding is consistent with the marketing literature results on brand loyalty. Nevertheless, it is important to note that our results should not be interpreted as evidence in favor of a brand loyalty effect; alternatively, they may indicate that the same unobserved factors that influenced the vehicle choice in the past, are present today. This is the well known problem of "state dependency vs. unobserved heterogeneity".
} 
was slightly negative $(-0.02)$, but highly insignificant ( $t$-statistic $=0.07$ ). To preserve the consistency of the approach with the hypothesis of random utility maximization, this parameter was imposed to the value of zero, and the model was reestimated without including the inclusive value term in the last stage. Since the specification choices and results are very similar to the ones discussed in Goldberg (1995), I refer the reader to that paper for more details and specification testing; in the following, I concentrate on those results that are most relevant for the analysis of the CAFE standard regulation. These are summarized in Table $2 .{ }^{36}$

Table 2: Selected Parameter Estimates from the Discrete Choice Model

\begin{tabular}{|c|c|c|c|}
\hline DOM/FOR & MARKET SEGMENT & NEW/USED & BUY/NOT BUY \\
\hline \# of Obs: 2944 & \# of Obs: 3143 & \# of Obs: 12635 & \# of Obs: 42152 \\
\hline $\begin{array}{r}\text { DOM: } 68 \% \\
\text { FOR: } 32 \%\end{array}$ & $\begin{array}{l}1: 15 \% \text { 2: } 23 \% \text { 3: } 18 \% \\
\text { 4: } 06 \% \text { 5: } 05 \% \text { 6: } 05 \% \\
\text { 7: } 22 \% \text { 8: } 05 \% \text { 9: } 02 \%\end{array}$ & $\begin{array}{l}\text { NEW: } 30 \% \\
\text { USED: } 70 \%\end{array}$ & $\begin{array}{r}\text { BUY: } 27 \% \\
\text { NOT BUY: } 73 \%\end{array}$ \\
\hline $\begin{array}{r}\text { Price: }-2.99(1.39) \\
\text { Fuel Cost: }-0.42(0.14)\end{array}$ & Incl: $0.89(0.04)$ & Incl: $0.4(0.09)$ & $\begin{array}{r}\text { Incl: }-0.02(0.3) \\
\text { (Constrained to } 0)\end{array}$ \\
\hline
\end{tabular}

The upper part of the table reports the number of observations at each estimation stage, as well as the frequency of the observed choices ${ }^{37}$.In the lower part of the table, I report the parameter estimates required in computing the substitution effects induced by CAFE and in evaluating consumer preferences for fuel efficiency (standard errors in parentheses). The price parameter estimates are in line with those reported in Goldberg (1995), and imply quite plausible own and cross price elasticities of demand. A noticeable difference from Goldberg (1995) is the coefficient estimate for the inclusive value term at the new/used stage; this estimate is much larger in this paper ( 0.4 instead of 0.01 ) implying higher substitution effects between new and used cars. From an environmental perspective, the fuel cost coefficient is of special interest; the estimated parameter implies that increasing the cost of a mile on a certain vehicle by 1 cent, ${ }^{38}$ reduces the probability of buying that vehicle type by ca. $10 \%$ on average, implying

\footnotetext{
${ }^{36}$ Table 2 repeats a subset of the results reported in Tables B1-B4 in Appendix B.

${ }^{37}$ The notation for the market segments is as follows: 1:Subcompacts, 2:Compacts, 3:Intermediate, 4:Standard, 5:Luxury, 6:Sports, 7:Pick-up Trucks, 8:Vans, 9:Other.

${ }^{38}$ Fuel cost is measured in cents per mile, and is computed as the product of regional gasoline prices and gallons per mile for each vehicle type.
} 
an average fuel cost elasticity of $-\mathbf{0 . 5}$. Thus, consumers seem to respond to changes in vehicle operating costs.

\section{IV.2 Results from the Estimation of the Utilization Model}

The results from the estimation of the utilization model (equation (3)) are reported in Table 3. Three alternative estimation methods were used. The first one is simple OLS (column 1); as noted earlier, this method will potentially lead to biased parameter estimates if the error terms of the discrete choice and the utilization models are correlated. The second column in Table 3 reports results from the reduced form approach, and the third column reports the results from the IV estimation. The list of instruments includes all the exogenous variables of the system and the estimated choice probabilities from the discrete choice model ${ }^{39}$.

The striking feature of the estimation results is that the effect of operating cost on vehicle utilization disappears once the endogeneity of the vehicle choice dummies is accounted for. Ordinary Least Squares yields a parameter estimate of -110.7 for fuel cost, implying a short run ${ }^{40}$ mileage elasticity of ca. $22 \%$. In addition, the OLS coefficients on various choice specific dummies are positive and significant, suggesting the presence of a portfolio effect. Both effects disappear once the reduced form, or the instrumental variables approach is employed; in the reduced form method, for example, the point estimate of the fuel cost coefficient drops to -57.2 , implying a mileage elasticity of only $11 \%$; in the instrumental variables approach the coefficient becomes positive. More importantly, the coefficient is in both cases highly insignificant, so that the hypothesis of a zero mileage elasticity cannot be rejected. The same results apply to the vehicle choice dummies, which also become insignificant when the reduced form or instrumental variables approach is applied. ${ }^{\mathbf{4 1}}$

\footnotetext{
${ }^{39}$ The standard errors were computed using White's formulas; this method yields unbiased standard errors.

${ }^{40}$ Since this elasticity is based on on the conditional (on vehicle choice) usage equation, it is best viewed as short run.

${ }^{41}$ Table 3 reports results from the most parsimonious specification. Various other specifications was experimented with, some of which included a larger set of vehicle attributes, such as vehicle price, size, horsepower, etc. None of the estimated coefficients for these attributes was, however, statistically significant, while the OLS parameter estimate for fuel cost was slightly lower, implying a mileage elasticity of ca. $16 \%$. Estimating these alternative specifications with instrumental variables or the reduced form method produces exactly the same pattern as in Table 3, namely the fuel cost coefficient becomes much smaller in absolute value, and both the fuel cost and vehicle choice dummies become insignificant. The results were also robust to an alternative specification, in which both regional and vehicle specific dummies were dropped from the estimation. These dummies belong to the utilization equation, by virtue of Roy's identity. Nevertheless, one might be concerned that they absorb all of the variation in FUELC, given that the latter is computed as the product of regional gasoline prices and MPG figures. However, without the dummies, the instrumental variables estimate of the fuel cost parameter remains essentially unchanged (24.9, with standard error 197.4$)$.
} 
Table 3: Estimation Results from the Utilization Model ${ }^{42}$

Dependent Variable: Miles per Quarter

Number of Observations: 2954

\begin{tabular}{|l|r|r|r|}
\hline Variables & OLS & Reduced Form & Instr. Variabl. \\
CONST & 3097.70 & 2965.25 & -2307.00 \\
& $(7.75)$ & $(13.10)$ & $(-0.41)$ \\
FUELC & -110.69 & -57.24 & 21.23 \\
& $(-2.07)$ & $(-0.15)$ & $(0.17)$ \\
CC1 & 138.10 & 8691.63 & 6738.73 \\
& $(0.55)$ & $(0.49)$ & $(1.22)$ \\
CC2 & 348.48 & -6962.23 & 4871.32 \\
& $(1.44)$ & $(-0.65)$ & $(0.76)$ \\
CC3 & 379.03 & -2144.52 & 5717.50 \\
& $(1.63)$ & $(-0.30)$ & $(0.98)$ \\
CC4 & 472.02 & 6952.48 & 6287.95 \\
& $(1.84)$ & $(0.47)$ & $(0.79)$ \\
CC5 & 496.41 & -1429.35 & 4327.11 \\
& $(1.93)$ & $(-0.35)$ & $(0.67)$ \\
CC6 & 75.42 & 1069.76 & 4488.20 \\
& $(0.29)$ & $(0.08)$ & $(0.89)$ \\
CC7 & 649.00 & 3564.54 & 5446.49 \\
& $(2.77)$ & $(0.62)$ & $(0.87)$ \\
CC8 & 206.92 & -2477.38 & 4600.97 \\
& $(0.79)$ & $(-0.32)$ & $(0.70)$ \\
AGE & -23.14 & -20.65 & -25.27 \\
& $(-6.75)$ & $(-5.76)$ & $(-2.04)$ \\
EDUC & 66.57 & 58.84 & 121.83 \\
& $(0.82)$ & $(0.77)$ & $(0.65)$ \\
FAMSIZE & 50.62 & 17.28 & -5.71 \\
& $(0.63)$ & $(0.28)$ & $(-0.04)$ \\
PERSLT18 & -80.58 & -59.99 & 16.56 \\
& $(-0.85)$ & $(-0.69)$ & $(0.10)$ \\
\hline
\end{tabular}

continued on the next page

\footnotetext{
${ }^{42} \mathrm{~T}$-statistics are reported in the parentheses. An explanation of the variable acronyms can be found in the Appendix.
} 
Table 3 (continued)

\begin{tabular}{|l|r|r|r|} 
Variables & OLS & Reduced Form & Instr. Variabl. \\
\hline & & & \\
NE & -291.25 & -356.55 & -391.37 \\
NC & $(-3.08)$ & $(-4.13)$ & $(-2.65)$ \\
& -8.89 & -51.66 & -36.81 \\
WE & $(-0.09)$ & $(-0.57)$ & $(-0.26)$ \\
& 108.74 & 73.29 & 103.21 \\
FEMALE & $(1.01)$ & $(0.76)$ & $(0.41)$ \\
& 39.54 & -36.71 & -11.32 \\
ASIAN & $(0.42)$ & $(-0.42)$ & $(-0.06)$ \\
& -418.67 & -455.32 & -638.01 \\
MINOR & $(-2.05)$ & $(-2.56)$ & $(-2.01)$ \\
& -276.00 & -215.63 & -404.85 \\
BLUEC & $(-2.13)$ & $(-1.72)$ & $(-1.40)$ \\
& -113.36 & -103.15 & -175.03 \\
UNEMPL & $(-1.09)$ & $(-0.96)$ & $(-0.93)$ \\
& 43.19 & 103.57 & 48.04 \\
BIGCITY & $(0.36)$ & $(0.88)$ & $(0.25)$ \\
& 14.43 & 32.75 & -3.50 \\
INCOM & $(0.18)$ & $(0.36)$ & $(-0.03)$ \\
& $-0.19 \mathrm{E}-02$ & $-0.14 \mathrm{E}-02$ & $0.15 \mathrm{E}-02$ \\
ASSET & $(-1.15)$ & $(-0.64)$ & $(0.58)$ \\
& $0.14 \mathrm{E}-02$ & $0.16 \mathrm{E}-02$ & $0.22 \mathrm{E}-02$ \\
AVAGE & $(1.30)$ & $(1.21)$ & $(1.30)$ \\
& -48.82 & -57.86 & -22.06 \\
AGENEW & $(-2.25)$ & $(-2.89)$ & $(-0.48)$ \\
& 45.98 & 52.97 & 20.11 \\
NOCAR & $(2.11)$ & $(2.64)$ & $(0.41)$ \\
& 331.25 & 361.73 & 369.57 \\
CARSTOCK & $(2.28)$ & $(1.70)$ & $(1.95)$ \\
& 169.46 & 170.04 & 137.22 \\
& $(2.80)$ & $(3.11)$ & $(1.10)$ \\
& & & \\
\hline
\end{tabular}

Table 4 reports the coefficients on fuel cost for alternative specifications, in which the "price per mile" variable is interacted with household characteristics. ${ }^{43}$ Of particular interest are

\footnotetext{
${ }^{43}$ The estimated coefficients for the remaining variables are almost identical to the basic specification reported in Table 3, and are omitted here for brevity. The full set of results is available upon request.
} 
the results for a specification in which fuel cost is interacted with car ownership dummies (upper part of Table 4). Two different fuel cost coefficients are estimated: one (FUELCM) for multi-vehicle households, and one for one-vehicle households (FUELC1). Approximately $17 \%$ of the sample households own only one automobile. Intuitively, one would expect multivehicle households to exhibit larger mileage demand elasticities for any single vehicle in their stock, as they can respond to a fuel price increase by driving their most fuel efficient cars more often. ${ }^{44}$ This expectation is indeed confirmed in Table 4; the point estimates for multi-vehicle households are substantially larger than the ones for one-vehicle households, which are found to be completely price inelastic, even in the OLS specification. If one considered the elasticity figure for one-vehicle households to be a good estimate of the elasticity that multi-vehicle households exhibit with respect to their entire stock, one would have to conclude, on the basis of Table 4, that mileage demand is totally unresponsive to changes in operating costs. This unresponsiveness is present even in the OLS regressions; the correction for simultaneity bias pushes the coefficients of the fuel cost variables (for both multi- and one-vehicle households) further towards zero.

\section{Table 4: Estimation Results from the Utilization Model when Fuel Cost is Interacted with Household Characteristics ${ }^{45}$}

Interactions of Fuel Cost with Number of Vehicles Owned
\begin{tabular}{|c|r|r|r|}
\hline Variables & OLS & Reduced Form & Instr. Variabl. \\
\hline & & & -11.10 \\
FUELCM & -124.10 & -57.10 & $(0.07)$ \\
& $(2.30)$ & $(0.13)$ & 145.40 \\
FUELC1 & -35.79 & -8.13 & $(0.04)$ \\
& $(0.61)$ & $(0.02)$ & \\
\hline
\end{tabular}

\footnotetext{
${ }^{44}$ It is important to note that the mileage demand elasticity here refers to a single vehicle in the stock ( $\boldsymbol{x}_{i}$ denotes miles driven on car $i$ ); the elasticity for the utilization of the total stock, however, should be substantially smaller. The reason multi-vehicle households are expected to be more price elastic than one-vehicle households with respect to any single car, is that they can substitute towards more fuel efficient cars within their existing stock rather than reducing their total driving; but this implies that their total mileage should be relatively unresponsive to fuel cost changes.

${ }^{45}$ The variable FUELCM is the product of fuel cost and a dummy variable which is equal to 1 for multi-vehicle households. FUELC1 is similarly defined for one-vehicle households. The variables FUINCL and FUINCH represent interactions of fuel cost with dummy variables corresponding to households with annual income below $\$ 30000$ and above $\$ 30000$, respectively. The numbers in parentheses are T-statistics.
} 
Interactions of Fuel Cost with Incorne

\begin{tabular}{|l|r|r|r|}
\hline Variables & OLS & Reduced Form & Instr. Variabl. \\
\hline & & & \\
FUINCL & -103.8 & 17.5 & 25.90 \\
& $(1.88)$ & $(0.04)$ & $(0.19)$ \\
FUINCH & -116.20 & -90.80 & 29.9 \\
& $(2.15)$ & $(0.24)$ & $(0.22)$ \\
& & & \\
\hline
\end{tabular}

The low elasticity estimate for mileage demand contrasts with Dahl and Sterner's (1991) broadly cited figure of 0.20 , though it is in agreement with some of the individual studies included in Dahl and Sterner's review. Given the plethora of alternative methodological approaches, sample periods and countries considered in previous work, a one-to-one comparison of our approach with previous studies is impossible. In interpreting our results in the context of the previous literature, however, the following observations may be of use:

First, our results should not be interpreted as evidence that consumers do not respond at all to fuel cost increases. The short run elasticity of gasoline demand is derived from a conditional vehicle usage equation; thus, the proper interpretation of our estimation results is that conditional on the vehicle choice the decision how much to drive is price inelastic. However, consumers alter their vehicle choices in response to changes in operating costs, as the results from the discrete choice model suggest. Since gasoline demand is determined by both utilization and fuel efficiency of the vehicle stock, this implies that the elasticity of gasoline demand in the longer run is higher.

Second, our results refer to the U.S, and to the 1984-1990 period. Comparisons with studies referring to different countries or sample periods may be misleading, for two reasons: First, one would expect gasoline demand elasticities to vary across countries; European countries with developed public transportation networks will presumably exhibit much larger elasticities than the U.S., where private car transportation is the only option in some areas. Second, there is no reason to believe that the utilization equation would be structurally stable over long time periods, especially if the latter include major shocks, such as the fuel price shocks of the 1970s. This is particularly relevant when our results are compared to those of studies referring to the 1970s, or when one tries to extrapolate our findings to historical time series phenomena. The fuel cost variation in our data is relatively small, compared to the one witnessed in the 1970s. Our results, properly interpreted, suggest that driving does not respond to fuel cost 
changes that lie within the range of variation in our data. It is, however, possible that a major shock (a major gasoline price increase, for example) induces a structural break. This is likely to be the case if there are high adjustment costs associated with a household changing their driving habits; for modest fuel price increases, the time costs of finding ways to reduce the miles travelled, by organizing car pooling, acquiring information about public transportation alternatives, coordinating with other household members, etc., may exceed the expected savings. Dramatic price increases, however, make the effort worthwhile. ${ }^{46}$

Finally, as mentioned earlier, the usage equation (3) is estimated for new cars alone. ${ }^{47} \mathrm{~A}$ priori, there is no compelling reason why the mileage demand elasticities associated with used cars should be different; yet, in the absence of any empirical results for used cars this possibility cannot be eliminated. As discussed earlier, the major factor driving the decision between new and used automobiles seems to be financial ability. This suggests that one reason the mileage demand elasticities might differ across these two car categories, is because of the interaction of price with income effects. To get a rough idea how important this interaction might be, equation (3) was reestimated replacing the fuel cost variable with two interaction terms between fuel cost and income (see Table 4): the variable FUINCL represents fuel cost for consumers with annual income less than $\$ 30,000$, while FUINCH denotes the fuel cost for consumers with income above $\$ 30,000$. The income threshold of $\$ 30,000$ is arbitrary, but it reflects the fact that consumers with income less than $\$ 30,000$ are less likely to buy a new car. ${ }^{48}$ As the lower part of Table 4 indicates, the point estimates are slightly higher for high income consumers, but the difference is not statistically significant. As before, the coefficients tend to zero once the endogeneity of

\footnotetext{
${ }^{46}$ Aggregate time series data on the average annual miles traveled per vehicle between 1960 and 1990 seem to support this interpretation; according to the AAMA Motor Vehicles Facts and Figures (various issues), the average mileage was 9,446 in 1960 and 10,272 in 1970. Between 1970 and 1975, the period that included the first oil price shock, the average mileage declined to 9,690. Between 1975 and 1980 fuel costs increased significantly because of the second energy shock, and average mileage declined further to 9,141 . After 1980 , fuel costs remained relatively stable and so did the average annual mileage. The latter increased by ca. 150 miles per year between 1980 and 1990 to reach 10,548 miles in 1990 . It is interesting to note that the modest fuel price decreases in 1985 and 1986 were not matched by an increase in mileage; mileage increased by only 2 miles between 1984 and 1985, and 65 miles between 1985 and 1986, despite a decrease in the per mile cost of 1.68 cents in this time interval. The per mile cost slightly increased in the 1986-1990 period, but annual mileage kept rising by ca. 200 miles per year. Of course, cross year comparisons do not control for other factors that may influence mileage demand, such as changes in demographics, so that the conclusions that can be drawn from them are only suggestive.

${ }^{47}$ Because we correct for simultaneity bias by instrumenting the vehicle specific attributes in the usage equation (using the predicted probabilities from the vehicle choice model as instruments), the focus on new cars does not imply sample selection bias in our results; however, the estimated elasticity cannot be interpreted as anything else but the elasticity for new cars only.

${ }^{48}$ Experimenting with alternative thresholds or multiple income brackets produced the same results.
} 
the vehicle attributes is accounted for.

These qualifications notwithstanding, the striking feature of our results is that the elasticity implied by the OLS regression is within the range of Dahl and Sterner's estimate; it is the simultaneity bias correction that pushes the elasticity estimates towards zero. This indicates that the methodological aspect may be the dominant factor in explaining the divergence of our estimates from previous studies.

In summary, the estimation results suggest that the same unobserved factors leading to the choice of fuel efficient cars lead to high vehicle utilization, and vice versa. This produces the negative correlation between operating cost and utilization captured in the OLS regression coefficients; mileage elasticities based on these coefficients are thus biased upwards. Accounting for the endogeneity of the vehicle choice dummies suggests that the mileage demand is in fact price inelastic. It seems that other factors, unrelated to the vehicle operating cost, are more important in explaining utilization. Driving distance to work is the one coming immediately to mind. Availability of public transportation is another. Unfortunately, our data set does not include any information on the characteristics of the work place, such as location or distance from home, nor does it report the state of the household residence. The parameter estimates for age and Northeast, however, are consistent with distance-to-work, and public-transportation based explanations respectively, as they suggest that older individuals drive less, and that average utilization in the Northeast, where the public transportation network is more developed than in the rest of the country, is lower.

\section{IV.3 Implications of the Demand Side Results for Environmental Regulation}

To evaluate the effects of alternative environmental policies, it is useful to express the total gasoline consumption of U.S. households as the product of two terms, Total Miles driven, and Gallons per Mile:

$$
\text { Total Gallons }=\text { Miles } \times(\text { Gallons per Mile })
$$

Policies aimed at reducing gasoline consumption can target either the first, or the second, or both components of this product. It has often been argued that policies aimed at reducing driving, such as an increase in the gasoline tax, are preferable, as they target fuel consumption in a direct and transparent way. The results from the discrete choice and utilization models speak directly to this issue. 
The parameter estimates of the utilization model suggest that mileage demand is affected by neither the operating cost, nor the composition of the vehicle stock. This finding has two implications with respect to environmental regulation. First, policies aimed at reducing driving by increasing the operating cost of vehicles (by increasing, for example, the gasoline $\operatorname{tax}^{49}$ ) are unlikely to be effective. Second, the beneficial effects of policies that shift the composition of the new car fleet towards more fuel efficient vehicles (CAFE standards, for example) are not offset by an increase in the utilization of the fuel efficient vehicles. This implies that policies with compositional effects are likely to be more effective than policies aimed at reducing gasoline consumption without altering the composition of the car sales.

Of course, policies with compositional effects will not reduce gasoline consumption if the compositional shift occurs in the direction of used, less fuel-efficient, cars. The results from the estimation of the discrete choice model are of direct relevance here. The low value of the coefficient on the inclusive value term at the "new vs. used" node implies that the substitution effects between new and used cars are relatively small. ${ }^{50}$ Similarly, the coefficient on the inclusive value term at the very first node (buy vs. not buy) is not significantly different from zero, implying no substitution effects between the "outside" good and cars; put differently, vehicle characteristics entering the subsequent nodes of the tree (such as prices of new cars) have no impact on the buy vs. not buy decision. A direct implication of this finding is that price changes resulting from the $\mathrm{CAFE}$ regulation will have no effect at all on the sum of the new and used car sales, they will cause small shifts in the allocation between new and used car sales, ${ }^{51}$ and will have substantial compositional effects within the fleet of new cars.

The above results do not necessarily imply that fuel efficiency standards are superior to an increase in gasoline taxes; the composition of the car sales depends itself on both the gasoline prices and the fuel efficiency of the new car fleet. As indicated by the parameter estimates of the discrete choice model, consumers do respond to both price and operating cost of new vehicles; while vehicle utilization does not depend on operating cost, vehicle choice does. A question of particular interest for environmental regulation is whether consumers appear to be "myopic",

\footnotetext{
${ }^{49}$ The gas tax increases we have in mind here, are ones of approximately the same order of magnitude as the fuel price variation observed in our data; as mentioned in the previous subsection, the consumer response to dramatic price increases (like the ones associated with the oil shortages of the 1970s) may well be different.

${ }^{50}$ Recall that this coefficient was estimated to be 0.4 for the the $1984-1990$ period. In earlier work, I estimated the same coefficient to be 0.01 for $1983-1987$. These two sets of results provide some weak evidence that the substitutability of used cars has increased during the 1980s; the results for the earlier years imply that consumers viewed new and used cars as almost completely distinct products.

${ }^{51}$ In other words, CAFE has no scrappage effects; consumers may decide to purchase a used instead of a new car, but they will not cancel a car purchase completely.
} 
in the sense that they respond more to current changes in vehicle prices, than to changes in fuel costs that are felt over several periods. As noted earlier, our empirical results imply an average fuel cost elasticity of -0.5 , while the average vehicle price elasticity is -3.01 . Hence, a proportional increase in vehicle prices will have a substantially larger effect on vehicle choice than a proportional increase in fuel costs. This calculation, however, ignores the fact that the absolute dollar amount associated with a proportional increase in vehicle prices is much larger than the one associated with a similar increase in fuel costs; the average vehicle price in 1987 was ca. $\$ 12,000$, while the average per year fuel costs were ca. $\$ 300$. A more informative calculation would, therefore, involve semi-elasticities rather than elasticities. Assuming a discount rate of $5 \%$, and an average vehicle holding period of 7 years, produces vehicle price, and fuel cost semi-elasticity estimates that are very similar in magnitude. Even though these calculations are sensitive to assumptions about vehicle holding periods and discount rates, the numbers used above seem realistic enough to safely say that we do not have any reason to believe that consumers are myopic. Hence, changes in operating costs can, from an environmental perspective, be as effective as changes in vehicle prices.

Operating costs can, in turn, be affected either by changes in the fuel efficiency of new vehicles as measured by Miles per Gallon, or by variations in the Price per Gallon for gas. Which of the two approaches is more effective in shifting the composition of the new car sales towards a more fuel efficient mix, cannot be judged without solving for the equilibrium of the model; This involves computing the aggregate consumer response to alternative policy scenarios, feeding this response back to the suppliers' profit maximization problem, and solving for the new equilibrium prices, market shares, and locational parameters. This task is undertaken in the last part of the paper, where the simulation results are reported.

\section{IV.4 Aggregate Market Shares, Average Fuel Efficiency, and Unit Variable Costs}

The predicted choice probabilities from the discrete choice model are used in conjunction with the population weights of the CES to compute aggregate demand and market shares. ${ }^{52}$ The results from this procedure are reported in Table 5; the left panel of the table reports the predicted figures, which are compared to the actual ones displayed in the right panel of the table.

\footnotetext{
${ }^{52}$ While the demand model was estimated for the $1984-90$ period, the aggregation procedure as well as the analysis of the fuel efficiency regulation refer only to 1985-90. As noted earlier, the year 1984 was excluded, because the empirical evidence suggests that the VER might still have been effective during that year.
} 
The comparison between predicted and actual shares is interesting for two reasons: First, it provides a measure of how representative of the U.S. population the CES sample is. Second, it gives us an idea as to whether our approach is promising in analyzing the effects of CAFE standards; given that the average fuel efficiency of the new car fleet depends on the allocation of sales across market segments, accurate model predictions of the market shares are essential for any further analysis of the fuel efficiency regulation. Table 5 reports results for two years, one towards the beginning of our sample period (1985) and one towards its end (1989); both years were associated with heated debates on the appropriateness of environmental standards. ${ }^{53}$ The aggregation results for the other years are similar.

\footnotetext{
${ }^{53}$ The year 1985 was the first year in which CAFE was in effect; Both GM and Ford were well below the prescribed standard of $27.5 \mathrm{MPG}$, and lobbied therefore intensely to reduce the standard to $26.0 \mathrm{MPG}$. The $1988 / 1989$ period was marked by proposals to make environmental standards stricter, by raising, among other things, the CAFE standard to 50 MPG by 2000 .
} 
Table 5: Aggregate Market Shares for 1985 and 1989

\begin{tabular}{|c|c|r|r||c|r|c|}
\hline \multicolumn{5}{|c||}{ Predicted } & \multicolumn{3}{c|}{ Actual } \\
\hline YR & Car Sales & Imports & \% Import & Car Sales & Imports & \% Import \\
\hline & & & & & & \\
85 & 9005437 & 2307111 & 25.6 & 11046243 & 2839226 & 25.7 \\
& 6403435 & 1831383 & 28.6 & 9713125 & 2698274 & 27.8 \\
& & & & & & \\
\hline YR & Truck Sales & Imports & \% Import & Truck Sales & Imports & \% Import \\
\hline & & & & & & \\
85 & 3398166 & 554418 & 16.3 & 4517668 & 805822 & 17.8 \\
89 & 4023453 & 675940 & 16.8 & 4779192 & 723871 & 15.1 \\
& & & & & & \\
\hline YR & Class & Cl.Share & $\%$ Import & Class & Cl.Share ${ }^{a}$ & $\%$ Import \\
\hline 85 & 1 & 27.9 & 49.1 & 1 & 28.5 & 47.0 \\
85 & 2 & 26.1 & 34.6 & 2 & 24.2 & 38.8 \\
85 & 3 & 27.5 & 3.0 & 3 & 28.0 & 2.2 \\
85 & 4 & 8.7 & 0.0 & 4 & 8.8 & 0.0 \\
85 & 5 & 9.8 & 24.2 & 5 & 10.5 & 26.2 \\
\hline 89 & 1 & 25.4 & 50.0 & 1 & 22.7 & 58.2 \\
89 & 2 & 31.3 & 33.2 & 2 & 35.0 & 23.9 \\
89 & 3 & 25.8 & 7.3 & 3 & 21.9 & 10.5 \\
89 & 4 & 9.0 & 0.0 & 4 & 9.8 & 0.0 \\
89 & 5 & 8.5 & 30.9 & 5 & 10.5 & 34.3 \\
\hline
\end{tabular}

aThese figures are taken from Ward's Automotive Yearbook

As is evident from Table 5, the model suffers from underpredicting total demand; this is exactly the same problem encountered in Goldberg (1995), and as discussed in that paper, it is due to the fact that the CES focuses on household purchases alone, ignoring fleet sales. Nevertheless, conditional on the prediction of total new car sales, the model predicts the shares corresponding to the various market segments, as well as the import shares, quite accurately. For the analysis of the fuel efficiency standards, it is the shares alone that matter in the computation of the average fuel efficiency. Underpredicting total demand does not therefore limit the applicability of the model.

This is also reflected in Table 6, in which the predicted average fuel efficiency of each manufacturer is reported. To facilitate comparisons, the second column repeats the CAFE standards for 1985-90. The third column reports the average fuel efficiency of domestic producers computed for their domestic products only, as implied by the model. The fourth column reports the same figure for those products classified as imports, while columns 5 and 6 report the cor- 
responding figures for foreign manufacturers; as noted earlier, according to the EPA import classification rules, no foreign brand classified as domestic during our sample period; therefore, column 5 in Table 6 is left blank. The computations suggest that the CAFE constraint was binding for the domestic producers for every single year between 1985 and 1990 for their domestic production, and had the strongest effects in 1985. The products classified as "imports" fared better, meeting the CAFE standard every year but 1985 and 1990, when the standard was highest. The implied CAFE penalties range from $\$ 5$ per domestically produced car in 1986 , to $\$ 130$ per car in 1985 . Similar computations for pick-up trucks indicate that the average fuel efficiency of domestic manufacturers was slightly below the CAFE standard in almost every year between 1985 and 1990 (ca. 19.5 MPG), for both domestically produced and imported trucks. The foreign manufacturers' average fuel efficiency, on the other hand, was well above the standard during the same period, for both passenger cars and pick-up trucks. These figures are fairly consistent with published data on the fuel efficiency of domestic and foreign corporations. 54

Table 6: Average Fuel Efficiency by Manufacturer as Implied by the Model

\begin{tabular}{|c|c|c|c|c|c|}
\hline Year & CAFE standard & \multicolumn{2}{|c|}{ Domestic Firms } & \multicolumn{2}{c|}{ Foreign Firms } \\
\hline & & Domestic & Imports & Domestic & Imports \\
\hline 85 & 27.5 & 24.9 & 27.1 & n.a. & 29.1 \\
86 & 26.0 & 25.9 & 26.8 & n.a. & 28.9 \\
87 & 26.0 & 25.0 & 26.0 & n.a. & 28.9 \\
88 & 26.0 & 25.6 & 27.7 & n.a. & 26.7 \\
89 & 26.5 & 25.7 & 27.2 & n.a. & 27.7 \\
90 & 27.5 & 25.2 & 25.7 & n.a. & 27.9 \\
\hline
\end{tabular}

The final step of the empirical analysis involves solving the first order conditions for profit maximization for the unit variable costs. Note that according to the results of Table 6, firms are

\footnotetext{
${ }^{54} \mathrm{~A}$ direct comparison of the figures in Table 6 to published data is hampered by the fact that the latter are typically broken down by corporation, while our predicted fuel efficiencies refer to domestic firm averages. To get a rough idea about the accuracy of the model, the following back-of-the-envelope calculation was conducted: The officially reported fuel efficiency of each corporation was multiplied by the share of that corporation in the domestic car sales to construct a national average. For 1985, the relevant figures are $25.1 \mathrm{MPG}$ and $64 \%$ market share for GM, 25.9 MPG and 22\% market share for Ford, and 27.1 MPG and 14\% share for Chrysler, which average to 25.5 MPG. This figure is slightly above the 24.9 MPG implied by our model. Note, however, that the above calculation did not distinguish between domestically produced, and imported cars. Confining the computation to domestically produced cars alone, would bring the computed average further down. In later years, the predicted average fuel efficiencies in Table 6 generally lie below the averages reported in the Automotive News Market Data Book, but display similar trends in terms of the differences between domestic and foreign firms.
} 
- with one exception - never at the point where the constraint is exactly satisfied; ${ }^{\mathbf{5 5}}$ the exception refers to the average fuel efficiency of the imports of domestic firms in 1987. This implies, that with the exception of 1987 for domestic firms, the equilibrium occurs in the differentiable area of the profit function. Hence, we can apply the first order conditions given by (5) and (6) to compute the unit variable costs. Take, for example, the year 1989. In this year, domestic firms do not meet the standard for their domestic products, but the average fuel economy of their imports is well above it. Hence, $I_{1}=1$ and $I_{2}=0$ for domestic firms. The computation of unit costs is much easier for foreign firms, since these do not produce any products classified as domestic and they are well above the standard in every single year. The first order conditions for foreign firms are further simplified by the absence of the CAFE penalty terms; given that foreign firms meet the standard every year, their unit variable costs are equal to their marginal costs $\left(n c_{i}^{*}\right)$, and do not vary with quantity.

The results from the unit cost calculations can be found in Table 7, which reports unit variable costs, inclusive of CAFE penalties, for "domestic" and "foreign" production separately, for 1989 . The average CAFE penalty for domestically produced, American cars is $\$ 40$ per vehicle for this year.

The results in Table 7 are quite intuitive, as they indicate that production costs increase with vehicle size, and are highest for the market segment of luxury cars. A noteworthy feature of the unit cost figures is that production costs in the U.S. differ from costs abroad. As noted in Section II.2, this is a direct consequence of the existence of binding fuel efficiency standards. More interestingly, our model estimates variable costs for subcompacts, compacts, and intermediates to be lower abroad than in the U.S., while this pattern is reversed for larger and luxury cars. This implies that, were it not to avoid higher CAFE penalties, domestic manufacturers would move the production of small cars abroad, and keep the production of larger cars in the U.S.. ${ }^{56}$ The differing cost patterns for small and large cars suggest that the cost differences between domestic and foreign production are probably due to more than just differences in input prices (such as lower wages in foreign countries); the production of large cars could, for example, require specialized labor, or parts that are cheaper in the U.S. than abroad, while foreign countries may have a comparative advantage in the production of small cars, which they already produce for their local markets. For foreign manufacturers, no unit

\footnotetext{
${ }^{55}$ Though the estimated average fuel efficiencies differ from the actual ones, the above statement is also true for the figures reported in the Automotive News Market Data Book which refer to individual firms.

${ }^{56} \mathrm{Or}_{\mathrm{r}}$ more accurately, reduce the domestic content of small cars, and increase the domestic content of large cars.
} 
costs for domestically produced cars are estimated, since there are no foreign brands classified as "domestic".

\section{Table 7: Estimated Unit Variable Costs for 1989}

\begin{tabular}{|c|c|c|c|}
\hline Class & Firm Nationality & \multicolumn{2}{|c|}{ Cost (incl. CAFE Penalty) } \\
\hline & & Domestic & Imports \\
\hline 1 & DOM & 6033 & 5973 \\
1 & FOR & n.a. & 5005 \\
2 & DOM & 6552 & 6372 \\
2 & FOR & n.a. & 7463 \\
3 & DOM & 8190 & 8171 \\
3 & FOR & n.a. & 8222 \\
4 & DOM & 8204 & 8304 \\
5 & DOM & 14279 & 14526 \\
5 & FOR & n.a. & 17516 \\
6 & DOM & 7730 & 7912 \\
6 & FOR & n.a. & 8894 \\
7 & DOM & 8766 & 8744 \\
7 & FOR & n.a. & 4832 \\
8 & DOM & 10697 & 10675 \\
8 & FOR & n.a. & 6925 \\
9 & DOM & 9078 & 9056 \\
9 & FOR & n.a. & 7343 \\
\hline
\end{tabular}

Having retrieved the demand and utilization parameters as well as the unit costs, both inclusive and exclusive of CAFE penalties, the effects of alternative policy scenarios can now be addressed through simulations.

\section{The Effects of Alternative Policies}

In this section, the empirical model of Section III is used to evaluate three policy proposals that have been actively debated in recent years: 1. Abolishing the current CAFE program; 2. Replacing the CAFE standard by a powerful gas guzzler tax; and 3. Replacing the current fuel efficiency standards with higher gasoline taxes. The method used to address the effects of these policies is the one of counterfactual simulations. The parameter estimates obtained in the previous sections are substituted into the model which is then solved under alternative assumptions concerning the environmental policy in effect. All of the simulations considered in 
the following sections involve policy scenarios other than CAFE standards. The derivation of the new equilibrium for each of these cases is straightforward; The CAFE penalty terms are absent from the unit variable cost functions, so that unit variable costs are equal to marginal costs. Consequently, the allocation of production between "domestic" and "imports" is independent of environmental rules; firms choose the lower cost alternative, so that $\alpha_{i}=1$ if $n c_{i}>n c_{i}^{*}$ and $\alpha_{i}=0$ if $n c_{i}<n c_{i}^{*}$. The equilibrium is thus described by conditions (5) and (6), where the last two terms in each equation have dropped out. ${ }^{57}$

The data used in the simulations refer to 1989. This year was chosen for two reasons: First, it is relatively recent, so it provides us with a fairly good idea of what the effects of alternative policies would be if these were introduced now. Second, for 1989, the predicted aggregate market shares and fuel efficiency patterns fit the actual data quite well, indicating that the 1989 CES sample was truly representative of the U.S. population. ${ }^{58}$ Given the focus of this paper on the environmental and trade effects of the CAFE regulation, the subsequent discussion will focus on three types of questions. First, what are the effects of alternative policies on prices, and market shares? In particular, how does the composition of the new car fleet change in response to environmental regulation, and how large are the substitution effects towards used cars? Second, how is fuel efficiency affected by this compositional shift? Which policy yields the largest fuel consumption savings? Third, how is the allocation between "domestic" and "imported" products affected by alternative measures? How significant is the job protection function of fuel efficiency standards?

\section{V.1 The Effects of Abolishing CAFE Standards}

One way to assess the effects of the current CAFE standards is to solve the model as if no environmental regulation were in effect, and compare prices, market shares and fuel consumption to the ones implied by the model in the presence of CAFE standards. The results from this exercise are summarized in Table 8.

\footnotetext{
${ }^{57}$ This is because in the absence of the CAFE regulation the derivatives of the unit costs with respect to price and fraction of domestic production are zero.

${ }^{58} \mathrm{As}$ noted in the previous section, this is true for the other years too, though 1989 fits the data best. In any case, for the simulation exercise, the choice of the particular year is of secondary importance (as long as the sample for this year is fairly representative of the U.S. population), given that - by definition - simulations do not tell us what really happened during a year, but what would have happened, had the policy under consideration been implemented.
} 
Table 8: Effects of Abolishing the CAFE Standard Regulation in 1989

\begin{tabular}{|c|c|c|c|c|c|}
\hline Fuel Consumption & Used Car Sales & \multicolumn{4}{|c|}{ Corporate Average Fuel Economy } \\
\hline-- & & \multicolumn{2}{|c|}{ Domestic Firms } & \multicolumn{2}{|c|}{ Foreign Firms } \\
\hline & & Domestic & Imports & Domestic & Imports \\
\hline +19 mil. Gallons & $-0.5 \%$ & $-1.2 \mathrm{MPG}$ & $+0.3 \mathrm{MPG}$ & n.a. & $-0.2 \mathrm{MPG}$ \\
\hline
\end{tabular}

\begin{tabular}{|c|c|c|c|}
\hline (Domestic Firms only) & Prices & Market Shares $^{59}$ & Share of Domestic Production \\
\hline Subcompacts & $+0.5 \%$ & $-1.5 \%$ & $-59 \%$ \\
\hline Compacts & $+0.5 \%$ & $-1.4 \%$ & $-95 \%$ \\
\hline Intermediate & $-1.3 \%$ & $+4.7 \%$ & $+10 \%$ \\
\hline Standard & $-1.6 \%$ & $+6.0 \%$ & $+17 \%$ \\
\hline Luxury & $-1.8 \%$ & $+1.3 \%$ & $+05 \%$ \\
\hline Sports & $-2.2 \%$ & $+2.1 \%$ & $+01 \%$ \\
\hline Pick-up Trucks & $-0.6 \%$ & $+1.0 \%$ & $+01 \%$ \\
\hline Vans & $-0.0 \%$ & $+0.0 \%$ & $0 \%$ \\
\hline Other & $-0.1 \%$ & $+0.1 \%$ & $+04 \%$ \\
\hline
\end{tabular}

In the absence of CAFE standards, the last two terms in equation (6) would drop out, and so would the CAFE penalty terms in the unit variable cost formulas; consequently, firms would produce "domestic" products if $n c_{i}<n c_{i}^{*}$ and "imports" if $n c_{i}>n c_{i}^{*}$. The results in Table 7 indicate that the first condition is met for all passenger car categories of domestic firms but subcompacts and compacts. ${ }^{60} \mathrm{Hence}$, in the absence of the CAFE regulation, we would observe a decrease in the fraction of domestically produced subcompacts and compacts, and an increase in the fraction of domestically produced large cars. The last column in the bottom part of Table 8 reflects this shift in the allocation of production between domestic and imported products for the American brands. For foreign brands, there are no allocation effects, given that foreign firms were above the CAFE standard for 1989 anyway.

A first idea about the environmental impact of the CAFE regulation can be obtained by examining its effects on the average fuel efficiency of domestic and foreign firms; these effects

\footnotetext{
${ }^{60}$ The numbers reported in Table 7 include the CAFE penalty of $\$ 40$ per passenger car domestic manufacturers pay in 1989 on their domestic products. To calculate $n c_{i}$ (unit costs net of CAFE penalties) I subtract $\$ 40$ from the figures in column 3; for example, the unit variable costs for subcompacts are $6033-40=5993$. Since the CAFE standard is met for the imports of domestic firms, a similar calculation is not necessary for column 4. As mentioned earlier, light trucks faced a different standard of $20.5 \mathrm{MPG}$ in 1989 . The average fuel efficiency of domestically produced trucks was estimated to be 20 MPG in our model, implying CAFE penalties of \$25 per truck. This number is subtracted from the cost figures referring to light trucks in Table 7 to get the unit costs net of CAFE penalties.
} 
are largest for the domestic production of U.S. manufacturers, whose corporate average fuel efficiency would be lower by 1.2 MPG in the absence of CAFE standards. Note, however, that this number alone is insufficient for judging CAFE's effectiveness, as it includes the import classification shifts resulting from CAFE; a large part of the 1.2 MPG drop in the domestic car fuel efficiency is due to the fact that in the absence of CAFE, small, fuel efficient cars would be "imported" and hence excluded from the calculation of the average fuel efficiency of the domestic fleet. This creates the illusion that CAFE has led to enormous fuel savings when in fact most of the increase in the average fuel efficiency is due to the shift in the allocation between "domestic" and "imports". Nevertheless, there is also a fraction in this change of the average that reflects $\mathrm{CAFE}$ induced compositional shifts towards more fuel efficient vehicles. The lower panel of table 8 shows how these shifts come about.

In the absence of the CAFE regulation, domestic manufacturers would set higher prices for small, fuel efficient cars, and lower prices for large vehicles. As a result of these price changes, the composition of the new car fleet would shift towards more fuel inefficient cars, while the total sales of new cars would go up. The projected prices of import cars exhibit a similar pattern, but the magnitude of the predicted price effects is much smaller. Nevertheless, the impact on the import market shares would be quite significant; because domestic manufacturers are dominant in the categories of intermediate and standard cars, the price reductions of large cars resulting from abolishing the CAFE regulation would boost domestic sales at the expense of imported brands, whose combined market share would go down by a whole percentage point.

From an environmental point of view the most interesting projection refers to the total fuel consumption in the absence of CAFE standards. The change in aggregate fuel consumption is computed as the difference between total gallons consumed with, and total gallons consumed without $\mathrm{CAFE}$, according to the formula:

$$
\triangle \text { Gallons }=\sum_{h} \sum_{i} w^{h} * P_{i}^{h} *\left(1 / M P G_{i}\right) * M_{i l e s_{i}^{h}}-\sum_{h} \sum_{i} w^{h} * P_{i}^{\prime h} *\left(1 / M P G_{i}\right) * M i l e s_{i}^{\prime h}
$$

To compute total fuel consumption with and without CAFE, I sum the expected individual fuel consumption on each vehicle $i$, over consumer and vehicle types, after weighting each individual observation by the CES population weight $w^{h}$. The expected individual fuel consumption on vehicle $i$ is in turn given by the product of each consumer's probability of purchasing that vehicle type $\left(P_{i}^{h}\right)$, times the fuel efficiency of that vehicle $\left(1 / M P G_{i}\right)$, times the miles the household drives on that vehicle. Given that according to the results of the utilization 
model, mile consumption does not depend on vehicle choice, we need not worry about how the compositional shifts induced by the CAFE regulation affected mileage; the miles driven on each vehicle are household, but not vehicle specific $\left(\right.$ Miles $_{i}^{h}=$ Miles $_{i}^{\prime h}=$ Miles $^{h}$ ). Hence, in the fuel consumption calculations I use the reported mileage on the household's new vehicle as an estimate of Miles ${ }^{h}$. In the absence of any utilization effects, the change in the aggregate fuel consumption comes entirely from the compositional shift of car sales, reflected in the change of the purchase probability of each vehicle type from $P_{i}$ to $P_{i}^{\prime}$. As noted earlier, the vehicle choice model incorporates the outside good; hence the subscript $i$ denoting the vehicle type refers not only to new, but also to used cars. The inclusion of used cars in the fuel consumption calculations is essential, as CAFE leads to substitution towards used cars ${ }^{61}$ which have on average a lower fuel efficiency than new cars.

The results from these calculations, shown in the upper part of Table 8, indicate that CAFE standards have substantial effects on fuel consumption; without CAFE, the aggregate fuel consumption would be higher by approximately 19 Million Gallons per year.

\section{V.2 The Effects of Raising the Gas Guzzler Tax}

In this section I examine the effects of replacing the CAFE standard regulation by a powerful gas guzzler tax. Just like the CAFE standards, the gas guzzler tax was enacted in 1975 to encourage efficiency when fuel shortages were feared. The tax gradually tightened in the 1980s; in 1988 the Congress voted to double the tax beginning with the 1991 models. Table 9 shows the tax schedule for each of the years between 1985 and 1993.

In contrast to $\mathrm{CAFE}$, the gas guzzler tax is applied to individual models, and is paid by the consumer. In its current form, the tax attaches a severe monetary penalty to fuel inefficient cars with fuel economy below 22.5 MPG. The penalty starts with $\$ 1,000$ for cars in the 22.022.5 MPG bracket and reaches its maximum at $\$ 7,700$ for cars with fuel economy below 12.5 MPG. Despite these stiff "penalties", the environmental effects of the gas guzzler tax during our sample period (1985-1990) should be rather small, given that the number of vehicles affected by the tax is limited to a few models with relatively small market shares; in the 1987 model year, for example, only 18 makes were subject to the tax. The number rose to 24 in 1988 and 49 in 1989; from the 49 models subject to the tax in 1989, however, 43 were expensive European

\footnotetext{
${ }^{61}$ The substitution effects towards used cars should, however, be viewed as short run effects. In the longer run, one would expect the prices of used cars to rise in response to the higher demand, limiting the increase in the sales of second-hand cars. This effect would make the CAFE regulation even more effective.
} 
luxury models. This market segment is characterized by not only a small market share, but also a relatively low price elasticity of demand, so that the tax induced price increases are unlikely to initiate significant substitution towards more fuel efficient vehicles. But, on the other hand, recent gas guzzler tax increases were rarely motivated by environmental considerations; the 1988 tax increase was enacted to help pay for two other unrelated measures approved by the Senate.

Table 9: New Car Gas Guzzler Tax, 1985-1993 ${ }^{62}$

\begin{tabular}{|l|r|r|r|r|}
\hline MPG: At least-Less than & 1985 & $1986-90$ & 1991 and later & Simulation \\
\hline $0-12.5$ & 2,650 & 3,850 & 7,700 & 9,000 \\
$12.5-13.0$ & 2,650 & 3,200 & 6,400 & 9,000 \\
$13.0-13.5$ & 2,200 & 3,200 & 6,400 & 9,000 \\
$13.5-14.0$ & 2,200 & 2,700 & 5,400 & 9,000 \\
$14.0-14.5$ & 1,800 & 2,700 & 5,400 & 9,000 \\
$14.5-15.0$ & 1,800 & 2,250 & 4,500 & 7,700 \\
$15.0-15.5$ & 1,500 & 2,250 & 4,500 & 7,700 \\
$15.5-16.0$ & 1,500 & 1,850 & 3,700 & 6,400 \\
$16.0-16.5$ & 1,200 & 1,850 & 3,700 & 6,400 \\
$16.5-17.0$ & 1,200 & 1,500 & 3,000 & 5,400 \\
$17.0-17.5$ & 1,000 & 1,500 & 3,000 & 5,400 \\
$17.5-18.0$ & 1,000 & 1,300 & 2,600 & 4,500 \\
$18.0-18.5$ & 800 & 1,300 & 2,600 & 4,500 \\
$18.5-19.0$ & 800 & 1,050 & 2,100 & 3,700 \\
$19.0-19.5$ & 600 & 1,050 & 2,100 & 3,700 \\
$19.5-20.0$ & 600 & 850 & 1,700 & 3,000 \\
$20.0-20.5$ & 500 & 850 & 1,700 & 3,000 \\
$20.5-21.0$ & 500 & 650 & 1,300 & 2,600 \\
$21.0-21.5$ & 0 & 650 & 1,300 & 2,600 \\
$21.5-22.0$ & 0 & 500 & 1,000 & 2,100 \\
$22.0-22.5$ & 0 & 500 & 1,000 & 2,100 \\
$22.5-23.0$ & 0 & 0 & 0 & 1,700 \\
$23.0-23.5$ & 0 & 0 & 0 & 1,700 \\
$23.5-24.0$ & 0 & 0 & 0 & 1,300 \\
$24.0-24.5$ & 0 & 0 & 0 & 1,300 \\
$24.5-25.0$ & 0 & 0 & 0 & 1,000 \\
$25.0-25.5$ & 0 & 0 & 0 & 1,000 \\
25.5 and Over & 0 & 0 & 0 & 0 \\
\hline & & & & \\
\hline
\end{tabular}

Because of its progressiveness, and its negligible impact on American sales, the gas guzzler

\footnotetext{
${ }^{62}$ Source: Ward's Automotive News, 1993, p. 87
} 
tax has been much less controversial than CAFE standards. Not surprisingly, its biggest opponents are Germany and the European Community who criticized the tax increase as an unfair trade practice putting limits on consumer benefits. But the European Community's lobbying power in Washington is weak; and as Senator Bentsen noted, commenting on the expected price increases for models with six-figure price tags, such as Aston-Martin and Lamborghini: “... I have little sympathy for the impact on the buyer of such cars. I'm really not concerned about him paying another $\$ 3,800 . " 63$.

Though the gas guzzler tax has rather weak effects on fuel consumption in its current form, it could potentially provide a powerful environmental tool; its effects are direct, transparent, and of large magnitude. However, to be effective, the tax would have to include low fuel economy models that fall into more price elastic market segments, such as intermediate and standard sized cars. To assess the environmental potential of the tax, I therefore concentrate in the following on a policy scenario in which the tax is applied more broadly. This scenario is depicted in the last column of Table 9; the characteristic feature of this column is that the tax figures are similar in magnitude to those subsequent to 1990 , but the tax brackets are extended to include models with fuel economy below 25.5 MPG. From an environmental standpoint, this policy of extending the tax base should be more effective than a policy of increasing the tax within each previously defined bracket.

The simulation results for this scenario are depicted in Table 10. The simulation is based on the assumption that a powerful gas guzzler tax is replacing the current CAFE standards. As noted earlier, in the absence of CAFE, any incentives to shift the allocation between "domestic" and "imported" products to reduce the average fuel efficiency of the domestic fleet, disappear. Hence, producers will produce wherever the unit variable costs are lower, and the distinction between the domestic and imported fleet becomes irrelevant. Therefore, I only report the total fuel efficiency averages for the domestic and foreign firms in Table 10.

Table 10: Effects of an Increase in the Gas Guzzler Tax

\begin{tabular}{|c|c|c|c|}
\hline Fuel Consumption & Used Car Sales & \multicolumn{2}{|c|}{ Corporate Average Fuel Economy } \\
\hline & & Domestic Firms & Foreign Firms \\
\hline -48 mil. Gallons & $+0.6 \%$ & $+0.4 \mathrm{MPG}$ & $+0.3 \mathrm{MPG}$ \\
\hline
\end{tabular}

${ }^{63}$ The New York Times, March 22, 1988 


\begin{tabular}{|c|c|c|c|}
\hline Market Segment & Wholesale Prices & Transactions Prices & Market Shares \\
\hline Subcompacts & $+0.0 \%$ & $+0.0 \%$ & $+3.6 \%$ \\
Compacts & $+0.0 \%$ & $+0.0 \%$ & $+15.2 \%$ \\
Intermediate & $-0.1 \%$ & $+8.0 \%$ & $-12.1 \%$ \\
Standard & $-2.0 \%$ & $+18.0 \%$ & $-36.0 \%$ \\
Luxury & $-0.5 \%$ & $+19.1 \%$ & $-7.0 \%$ \\
Sports & $-0.6 \%$ & $+20.0 \%$ & $-6.0 \%$ \\
Pick-up Trucks & $+0.1 \%$ & $+0.1 \%$ & $+4.0 \%$ \\
Vans & $-1.4 \%$ & $+15.0 \%$ & $-15.3 \%$ \\
Other & $-1.0 \%$ & $+14.0 \%$ & $-16.7 \%$ \\
\hline
\end{tabular}

The first question of interest considers the incidence of the tax; if auto manufacturers respond to the tax increase by lowering the wholesale prices of their vehicles, the transactions price increase induced by the tax will be lower than the tax amounts in the last column of Table 9. The second column in the lower panel of Table 10 assesses the importance of this effect; the new gas guzzler tax affects the prices of intermediate, standard, luxury and sports passenger cars, as well as the prices of vans and utility vehicles. ${ }^{64}$ The wholesale prices of all these vehicle classes decrease slightly as a result of the tax; the effect is largest for the most price elastic classes (standard and vans), and lower for luxury and sports cars. This decrease of the wholesale prices, even though small in magnitude, implies that part of the gas guzzler tax cost is born by the producer. The largest part, however, is born by the consumer. Column 3 of Table 10 reports the increase in transactions prices; the increase is substantial, especially for the market segments of standard sized, luxury and sports cars. The higher prices of the cars included in these classes induce substitution towards more fuel efficient vehicles; as evident from the third column of Table 10, the big winner is the market segment of compacts with a $15 \%$ increase in their market share. Subcompact sales also increase, but by a smaller percentage of $3.6 \%$. The price increases also encourage substitution towards used cars; but as with CAFE standards, these substitution effects are weak (used car sales increase by only $0.6 \%$ ). Note that the large magnitude of the substitution effects implied by the powerful gas guzzler tax are due to the fact that the tax applies to the price elastic classes of intermediate and standard sized cars; though the tax amounts applied to these market segments are not higher than the ones currently applied to the European luxury automobiles, the higher price elasticities of demand for non-luxury cars lead to larger substitution effects towards compacts. ${ }^{65}$

\footnotetext{
${ }^{64}$ Because off-road users, such as farmers, loggers and miners are excluded from the tax, and because a large fraction of these users presumably uses pick-up trucks, the simulation excludes trucks from the gas guzzler tax; in contrast to the current regulation, however, the gas guzzler tax considered in the simulation applieg to vans and utility vehicles.

${ }^{65}$ The average price elasticity for models in the intermediate and standard sized classes is -4.0 , as opposed to
} 
These substitution effects translate to significant fuel savings. Using the method described in the previous subsection to compute fuel consumption with and without the more powerful version of the gas guzzler tax, the resulting fuel savings are estimated to be approximately 48 million Gallons, more than twice the amount saved by CAFE. The average fuel economies of American and foreign brands increase by 0.4 and 0.3 MPG respectively. In summary, a powerful version of the gas guzzler tax applying to a wide range of relatively fuel inefficient vehicles appears to be an extremely effective environmental tool.

\section{V.3 The Effects of Raising Gasoline Prices}

The final policy scenario to be considered in the simulations involves an increase in the gasoline taxes. CAFE opponents have often expressed the view that replacing the fuel economy regulation by higher gasoline taxes would provide a more effective environmental policy that would target fuel consumption directly. Our earlier results suggest that an increase in the vehicle operating cost is unlikely to affect utilization in any noticeable manner. Yet, it is possible that the compositional effects of higher gasoline prices outweigh those of the CAFE regulation. Contrary to the CAFE standards, gasoline taxes affect not only new but also used cars, so that there is no reason to expect any substitution towards less fuel efficient, used cars when taxes are raised.

To compare the environmental effects of a gasoline tax increase to those of the CAFE standards, we posed the following question: How large would a gas tax increase have to be in order to achieve the same fuel savings as with the CAFE regulation? According to our results, this increase would have to be extremely high: $780 \%$. As noted earlier, the vehicle choice estimation results do not suggest consumer myopia. The primary reason for the $780 \%$ figure is simply that the absolute dollar amounts associated with changes in fuel taxes are miniscule compared to those associated with vehicle price changes.

A second reason for the large magnitude of the required gasoline tax increase, is related to its effects on vehicle prices. Note that in the case of CAFE standards all price changes work in the same direction; the prices of small cars slightly decrease, the prices of large cars increase, and these price changes combined induce a shift towards smaller, more fuel efficient cars. In the case of a gasoline price increase, the price effects work in the opposite direction from the fuel cost effects; in particular, our results suggest that in response to a gasoline price increase the -1.2 elasticity estimated for luxury and sports cars. 
manufacturers lower the relative prices of luxury and standard sized cars; while these price decreases are quite small, they partly offset the negative impact of higher fuel prices on the demand for these market segments.

In short, our results suggest that in order to achieve noticeable changes in fuel consumption through a gasoline tax increase, the increase has to be substantial. Whether such a policy is politically feasible, given the regressivity of the gas tax, is questionable.

\section{Conclusions and Further Research}

Environmental policies aimed at reducing automobile fuel consumption have two aspects: a "utilization" aspect that concerns the miles driven on the current car fleet, and a "compositional" aspect that is related to the relative sales volume of vehicle types with different fuel efficiencies. The goal of this paper was to provide an evaluation of the CAFE standards in the automobile industry in terms of these two aspects. The empirical analysis suggested that for relatively small changes in fuel costs, utilization effects are negligible; therefore, policies oriented towards shifting the composition of the car fleet towards more fuel efficient vehicles seem more promising. With this in mind, the effects of the CAFE regulation were computed and compared to the ones of alternative policy measures. The basic conclusion is that the current standards - despite the presence of substitution effects towards used cars - were quite effective in reducing fuel consumption. Nevertheless, the fuel savings would be substantially larger if the CAFE standard regulation were replaced by a powerful gas guzzler tax. Gasoline taxation can also be effective as an environmental policy tool; but for the taxation to have noticeable effects on fuel consumption, the tax increases will have to be substantial. Of course, the choice of the appropriate environmental policy is not determined by environmental concerns alone. A powerful gas guzzler tax of the form described in Section V.2 is likely to meet the strong resistance of auto manufacturers just as was the case with CAFE standards; a substantial increase in gasoline taxes would probably cause a public outcry. The strong progressiveness of the gas guzzler tax and CAFE standard regulation, however, make these two measures better candidates for a politically viable environmental policy than the gasoline tax (traditionally viewed as regressive $\left.{ }^{66}\right)$.

The trade effects of the current CAFE standards were also found to be quite significant.

\footnotetext{
${ }^{66}$ The view that the gasoline tax is regressive has recently been challenged by Poterba (1991). Poterba relates gasoline expenditures to household expenditure rather than income, arguing that the former is a better proxy for permanent income, and finds that outlays for gasoline are roughly proportional to household spending.
} 
Whether the CAFE regulation has a job protection function is, however, ambiguous. While CAFE encourages keeping the production of small cars in the U.S., it also encourages moving the production of large cars abroad. Moreover, the simulation results indicate that the import shares rise as a result of the current $\mathrm{CAFE}$ regulation, reducing the profits of domestic manufacturers even further.

To the extent that the supply side of the automobile market model focused on price and domestic content decisions conditional on product types, the results should be interpreted with caution. As was emphasized earlier, the environmental effects of the CAFE regulation discussed in this paper are best viewed as short run effects; in the longer run the adjustment process to environmental policies is more complex as manufacturers may alter vehicle characteristics or introduce new technologies in response to stricter regulation. Another limitation of the present analysis concerns the aggregation of product types across manufacturers. Unfortunately, the current computational technology does not allow us to solve for both equilibrium prices and locational parameters when products are further disaggregated; therefore, it is not possible to assess the regulation's impact on each manufacturer separately, via simulations. Finally, our analysis abstracts from other policies that have been simultaneously in effect, such as emissions standards, policies to encourage the early scrappage of old vehicles, etc. Future research facilitated by the collection of better data and improvements in the computational technology may be able to address these shortcomings. 


\section{References}

[1] AAMA Motor Vehicles Facts and Figures, annual, 1984-1990.

[2] Automotive News Market Data Book, annual, 1984-1990.

[3] Berkovec, J. (1985a): "New car sales and used car stocks: a model of the automobile market", Rand Journal of Economics, Vol. 16, No. 2, 1985.

[4] Blair, R. et al (1984): "The Impact of Improved Mileage on Gasoline Consumption", Economic Inquiry 22, 209-217.

[5] Bresnahan, T. and D. Yao (1985): “The Nonpecuniary Costs of Automobile Emissions Standards", Rand Journal of Economics 16, 437-455.

[6] Crandall, R.W. (1990): "The Changing Rationale for Motor Vehicle Fuel-Economy Regulation", Regulation, Fall 1990, v13n3, 10-13.

[7] Crandall, R.W. and J. Graham (1989): "The Effect of Fuel Economy Standards on Automobile Safety", Journal of Law and Economics, v32n1, 97-118.

[8] Crandall, R.W., Gruenspecht, H.K., Keeler, T.E. and L.B. Lave (1986): "Regulating the Automobile", Washington, Brookings Institution.

[9] Crandall, R.W. (1985): "Why Should We Regulate Fuel Economy at All?", Brookings Review, Spring 1985, v3n3, 3-7.

[10] Dahl, C. and T. Sterner (1991): "A Survey of Econometric Gasoline Demand Elasticities", International Journal of Energy Systems 11, 53-76.

[11] Dubin, J. and D. McFadden (1984): "An Econometric Analysis of Residential Appliance Holdings and Consumption", Econometrica, Vol. 52, March 1984.

[12] Goldberg, P.K. (1995): "Product Differentiation and Oligopoly in International Markets: The Case of the U.S. Automobile Industry", Econometrica, July 1995, 891-951.

[13] Greene, D.L. (1990): "CAFE or Price?: An Analysis of the Effects of Federal Fuel Economy Regulations and Gasoline Price on New Car MPG, 1978-89", Energy Journal, v11n3, 37-57.

[14] Gruenspecht, H. (1982): "Differentiated Regulation: The Case of Auto Emission Standards", American Economic Review 72, 328-331.

[15] Kahn, M. (1994): "Differentiated Regulation's Impact Revisited: Scrappage Rates of 1970s Cars in the 1980s", Columbia University, mimeo.

[16] Kwoka, J. (1983): "The Limits of Market-Oriented Regulatory Techniques: The Case of Automobile Fuel Economy", Quarterly Journal of Economics, 695-704.

[17] Mannering, F. and C. Winston (1985): "A Dynamic Empirical Analysis of Household Vehicle Ownership and Utilization", Rand Journal of Economics, Vol. 16, No. 2, Summer 1985.

[18] Mayo, J. and J. Mathis (1988): "The Effectiveness of Mandatory Fuel Efficiency Standards in Reducing the Demand for Gasoline", Applied Economics, v20n2, 211-219. 
[19] McFadden, D. (1981) : "Econometric Models of Probabilistic Choice", in: "Structural Analysis of Discrete Data with Econometric Applications", eds. C. Manski and D. McFadden, MIT Press.

[20] Passell, P. (I995) : “Were the Government's mileage standards for cars a mistake?", New York Times C2, April 6, 1995.

[21] Poterba, J. (1991) : "Is the Gasoline Tax Regressive?", NBER Working Paper 3578, January 1991.

[22] Yee, J. (1991): "Effect of Consumption Standards on U.S. Gasoline Consumption", Journal of Policy Modelling, v13n2, 205-227.

[23] Ward's Automotive Yearbook, annual, 1984-1990.

[24] Wheaton, W. (1982): "The long-run structure of transportation and gasoline demand", Bell Journal of Economics, Fall 1982, 439-454. 


\section{APPENDIX A: DATA}

\section{List of Variables Used In The Estimation}

A) Household characteristics
AGE Age of Household Head
EDUC $\quad 1$ if attended college
FEMALE 0: male, 1: female
INCOM Household income after taxes
ASSET Total Assets (Checking/Savings Accounts
FAMSIZE Family Size
PERSLT18 Number of Persons under 18
BIGCITY 1 if more than 1.25 million population size
ASIAN 1 if Asian
MINOR 1 if Black or Hispanic
BLUEC 1 if Blue Collar
UNEMPL 1 if unemployed
NE $\quad 1$ if Northeast
NC $\quad 1$ if Northcentral
WE $\quad 1$ if West
CARSTOCK Number of cars owned before new vehicle was purchased or before household was interviewed
NOCAR $\quad 1$ if no car owned before
AVAGE Average Age of the existing stock of cars
AVAGES Square of AVAGE
AGENEW Age of the newest car in the stock before purchase was made
AGENEWS Square of AGENEWS
POWN $\quad 1$ if household has purchased same vehicle type in the past

B) Vehicle Characteristics and Interactions with Household Characteristics ${ }^{1}$
SIZE
Square Root of (Length $\times$ Width)
SIZEF
Size $x$ Famsize
WEIGHT
HP Horsepower

(continued on next page)

\footnotetext{
${ }^{1}$ All vehicle characteristica are sales-weighted averages by vehicle class.
} 
B) Vehicle Characteristics... (continued)

\begin{tabular}{|c|c|}
\hline HPW & $\begin{array}{l}\text { Horsepower/Weight (Measure of engine power } \\
\text { and acceleration) }\end{array}$ \\
\hline HPWYOUNG & Horsepower/Weight if household head is less than 30 \\
\hline CYL & Number of cylinders \\
\hline FUELC & $\begin{array}{l}\text { 1/Miles per Gallon (city estimate) x Regional Gasoline Price } \\
\text { (incl. taxes). The Gasoline Price is for Unleaded } \\
\text { Regular, taken from the Statistical Abstract. }\end{array}$ \\
\hline TRANS & 1 if car comes with automatic transmission \\
\hline PS & 1 if car has power steering \\
\hline AIRC & 1 if car has airconditioning \\
\hline PRICE & Vehicle Price \\
\hline $\mathrm{CC} 1-\mathrm{CC} 8$ & Dummies corresponding to classes 1 to 8 \\
\hline CCS & Dummy for Small Cars (Subcompacts and Co \\
\hline CCL & Dummy for Large Cars (Standard, Light Trucks and Vans) \\
\hline CCLX & Dummy for Expensive Cars (Luxury and Sports) \\
\hline
\end{tabular}

C) Other

D85-D90 Year Dummies

D1-D31 Dummies corresponding to the interview period of each household. For example, D1 refers to households interviewed between $83: 2$ and $84: 1, D 2$ to the ones interviewed between $83: 3$ and $84: 2$, and so on.

MACY Regional Disposable Personal Income per Capita (annual, Source: Statistical Abstract)

UNEMPLR Regional Unemployment Rate (annual, Source: BLS, "Geographic Profile of Employment and Unemployment")

AUTOFINT Average Interest Rate for (New and Used) Car Loans, (annual, Source: Federal Reserve Board, "Annual Statistical Digest")

CINCL1-9 Inclusive values for each market segment at the class choice node NINCL Inclusive value for new cars at the new/used node BINCL Inclusive value for buying a car at the buy/not buy node 


\section{APPENDIX B}

Results from the Demand Estimation

Table B1: Foreign vs. Domestic

0: Domestic

1: Foreign

Variable Parameter Standard T-Statistic

\begin{tabular}{lrrr} 
& Estimate & Error & \\
\hline POWN & 0.667 & 0.066 & 10.055 \\
PRICE & -2.991 & 1.390 & -2.150 \\
FUELC & -0.425 & 0.138 & -3.081 \\
HPW & 0.024 & 0.014 & 1.714 \\
SIZE & 0.023 & 0.016 & 1.449 \\
TRANS & -0.497 & 0.344 & -1.444 \\
PS & 0.899 & 0.181 & 4.957 \\
AIRC & -0.275 & 0.360 & -0.763 \\
C1 & -1.990 & 0.319 & -6.244 \\
AGE1 & -0.006 & 0.004 & -1.650 \\
EDUC1 & 0.506 & 0.106 & 4.777 \\
FAMSIZE1 & -0.025 & 0.034 & -0.738 \\
NE1 & -0.071 & 0.135 & -0.525 \\
NC1 & -0.575 & 0.136 & -4.216 \\
WE1 & 0.535 & 0.131 & 4.074 \\
ASIAN1 & 0.899 & 0.374 & 2.406 \\
MINOR1 & 0.374 & 0.178 & 2.104 \\
BLUEC1 & -0.287 & 0.135 & -2.128 \\
UNEMPL1 & -0.181 & 0.187 & -0.967 \\
BIGCITY1 & 0.143 & 0.106 & 1.351 \\
INCOM1 & 0.428 & 0.201 & 2.127 \\
D851 & -0.355 & 0.187 & -1.896 \\
D861 & 0.327 & 0.181 & 1.806 \\
D871 & 0.212 & 0.187 & 1.129 \\
D881 & -0.090 & 0.207 & -0.436 \\
D891 & -0.182 & 0.190 & -0.959 \\
D901 & 0.159 & 0.202 & 0.785 \\
CCS1 & 2.186 & 0.184 & 11.905 \\
CCL1 & -0.810 & 0.372 & -2.177 \\
CCLX1 & 1.726 & 0.213 & 8.092
\end{tabular}


Table B2: Class Choice

1-9: Class 1 - Class 9

\begin{tabular}{lrrr} 
Variable & $\begin{array}{r}\text { Parameter } \\
\text { Estimate }\end{array}$ & $\begin{array}{c}\text { Standard } \\
\text { Error }\end{array}$ & T-Statistic \\
\hline CINCL & 0.890 & 0.004 & 22.250 \\
C2 & 0.431 & 0.246 & 1.750 \\
AGE2 & 0.007 & 0.004 & 1.573 \\
FAMSIZE2 & -0.108 & 0.043 & -2.502 \\
BIGCITY2 & -0.050 & 0.120 & -0.417 \\
INCOM2 & -0.008 & 0.276 & -0.031 \\
BLUEC2 & -0.083 & 0.157 & -0.533 \\
C3 & -1.247 & 0.428 & -2.914 \\
AGE3 & 0.040 & 0.005 & 8.669 \\
FAMSIZE3 & -0.097 & 0.046 & -2.117 \\
BIGCITY3 & -0.121 & 0.127 & -0.949 \\
INCOM3 & 0.018 & 0.286 & 0.063 \\
BLUEC3 & 0.054 & 0.165 & 0.327 \\
C4 & -2.958 & 0.635 & -4.660 \\
AGE4 & 0.053 & 0.006 & 8.681 \\
FAMSIZE4 & -0.192 & 0.068 & -2.819 \\
BIGCITY4 & 0.004 & 0.177 & 0.021 \\
INCOM4 & 0.769 & 0.363 & 2.118 \\
BLUEC4 & -0.173 & 0.255 & -0.677 \\
C5 & -2.015 & 0.865 & -2.330 \\
AGE5 & 0.045 & 0.006 & 7.096 \\
FAMSIZE5 & -0.202 & 0.070 & -2.901 \\
BIGCITY5 & 0.111 & 0.184 & 0.602 \\
INCOM5 & 1.527 & 0.331 & 4.607 \\
BLUEC5 & -1.041 & 0.351 & -2.966 \\
C6 & -0.779 & 0.514 & -1.517 \\
AGE6 & -0.003 & 0.007 & -0.407 \\
FAMSIZE6 & -0.216 & 0.074 & -2.912 \\
BIGCITY6 & 0.140 & 0.194 & 0.721 \\
INCOM6 & 1.115 & 0.396 & 2.907 \\
BLUEC6 & -0.038 & 0.257 & -0.148 \\
& & & \\
& & & $c o n t i n u e d$
\end{tabular}


Table B2: Class Choice (continued)

\begin{tabular}{lrrr} 
Variable & $\begin{array}{r}\text { Parameter } \\
-\end{array}$ & $\begin{array}{c}\text { Standard } \\
\text { Estimate }\end{array}$ & T-Statistic \\
\hline C7 & 0.483 & 0.391 & 1.236 \\
AGE7 & 0.002 & 0.005 & 0.446 \\
FAMSIZE7 & 0.024 & 0.043 & 0.552 \\
BIGCITY7 & -0.459 & 0.123 & -3.749 \\
INCOM7 & 0.270 & 0.278 & 0.971 \\
BLUEC7 & 0.511 & 0.148 & 3.454 \\
C8 & -2.000 & 0.530 & -3.775 \\
AGE8 & 0.010 & 0.007 & 1.387 \\
FAMSIZE8 & 0.205 & 0.061 & 3.349 \\
BIGCITY8 & -0.318 & 0.194 & -1.639 \\
INCOM8 & 0.577 & 0.401 & 1.438 \\
BLUEC8 & -0.431 & 0.276 & -1.561 \\
C9 & -0.980 & 0.572 & -1.712 \\
AGE9 & -0.019 & 0.011 & -1.716 \\
FAMSIZE9 & -0.015 & 0.090 & -0.170 \\
BIGCITY9 & -0.284 & 0.259 & -1.094 \\
INCOM9 & 2.022 & 0.426 & 4.737 \\
BLUEC9 & -0.515 & 0.398 & -1.293
\end{tabular}


Table B3: New vs. Used

0: Used

1: New

\begin{tabular}{lrrr} 
Variable & $\begin{array}{r}\text { Parameter } \\
\text { Estimate }\end{array}$ & $\begin{array}{c}\text { Standard } \\
\text { Error }\end{array}$ & T-Statistic \\
\hline C1 & 13.797 & 3.812 & 3.619 \\
NINCL1 & 0.401 & 0.090 & 4.440 \\
D851 & 0.830 & 0.219 & 3.786 \\
D861 & 2.184 & 0.562 & 3.884 \\
D871 & 2.549 & 0.660 & 3.860 \\
D881 & 1.623 & 0.426 & 3.813 \\
D891 & 1.496 & 0.442 & 3.382 \\
D901 & 2.137 & 0.598 & 3.571 \\
AGE1 & 0.015 & 0.002 & 8.978 \\
EDUC1 & 0.547 & 0.050 & 10.879 \\
MINOR1 & -0.121 & 0.077 & -1.561 \\
BLUEC1 & -0.320 & 0.053 & -6.059 \\
UNEMPL1 & -0.133 & 0.074 & -1.796 \\
BIGCITY1 & 0.246 & 0.042 & 5.809 \\
INCOM1 & 0.854 & 0.106 & 8.020 \\
ASSET1 & 0.704 & 0.096 & 7.310 \\
NOCAR1 & -1.088 & 0.099 & -11.001 \\
CARSTOCK1 & -0.136 & 0.029 & -4.614 \\
AVAGE1 & -0.066 & 0.032 & -2.080 \\
AVAGES1 & -0.004 & 0.002 & -1.764 \\
AGENEW1 & -0.032 & 0.027 & -1.205 \\
AGENEWS1 & 0.002 & 0.002 & 1.122 \\
UNEMPLR1 & -0.311 & 0.067 & -4.640 \\
MACY1 & -0.987 & 0.332 & -2.972
\end{tabular}


Table B4: Buy vs. Not Buy

0: Not Buy

1: Buy

\begin{tabular}{lrrr} 
Variable & $\begin{array}{r}\text { Parameter } \\
\text { Estimate }\end{array}$ & $\begin{array}{r}\text { Standard } \\
\text { Error }\end{array}$ & T-Statistic \\
\hline C1 & 8.625 & 8.342 & 1.034 \\
AGE1 & -0.011 & 0.001 & -10.967 \\
EDUC1 & -0.229 & 0.030 & -7.550 \\
FAMSIZE1 & 0.210 & 0.008 & 24.958 \\
NE1 & 0.067 & 0.086 & 0.782 \\
NC1 & 0.048 & 0.061 & 0.786 \\
WE1 & 0.201 & 0.180 & 1.117 \\
FEMALE1 & -0.301 & 0.030 & -10.015 \\
ASIAN1 & -0.389 & 0.094 & -4.155 \\
MINOR1 & -0.427 & 0.045 & -9.544 \\
UNEMPL1 & -0.515 & 0.043 & -12.064 \\
BIGCITY1 & -0.200 & 0.027 & -7.368 \\
INCOM1 & 0.610 & 0.067 & 9.005 \\
ASSET1 & 0.499 & 0.056 & 8.782 \\
NOCAR1 & 3.383 & 0.069 & 48.920 \\
CARSTOCK1 & 0.178 & 0.019 & 9.416 \\
AVAGE1 & 0.048 & 0.018 & 2.697 \\
AGENEW1 & 0.009 & 0.015 & 0.592 \\
AVAGES1 & -0.003 & 0.001 & -2.610 \\
AGENEWS1 & 0.002 & 0.001 & 1.780 \\
UNEMPLR1 & 0.122 & 0.099 & 1.230 \\
MACY1 & -16.230 & 7.220 & -2.240 \\
AUTOFINT1 & -0.250 & 0.070 & -3.560 \\
D2-D31 Dummies & & & \\
(All of them highly significant) & & \\
& & &
\end{tabular}

